\title{
ESTUDO COMPARATIVO DO EFEITO DO ULTRA-SOM TERAPÊUTICO DE 1MHZ COM FREQÜÊNCIA DE REPETIÇÃO DE PULSO A 100 HZ E 16 HZ NO REPARO DE OSTEOTOMIA POR ESCAREAÇÃO EM TÍBIA DE RATO.
}

Dissertação apresentada ao Programa de PósGraduação Interunidades em Bioengenharia Escola de Engenharia de São Carlos, Faculdade de Medicina de Ribeirão Preto e Instituto de Química de São Carlos da Universidade de São Paulo para a obtenção do título de Mestre em Bioengenharia.

Orientador: Dr. Nivaldo Antonio Parizotto

\section{SÃO CARLOS}


Ficha catalográfica preparada pela Seção de Tratamento da Informação do Serviço de Biblioteca - EESC/USP

D726e Estudo comparativo do efeito do ultra-som terapêtico de $1 \mathrm{MHz}$ com freqüência de repetição de pulso a $100 \mathrm{~Hz}$ e $16 \mathrm{~Hz}$ no reparo de osteotomia por escareação em tíbia de rato / Estela Sant'Ana Vieira Douat. -- São Carlos, 2004 .

Dissertação (Mestrado) -- Faculdade de Medicina de Ribeirão Preto/Instituto de Química de São Carlos/Escola de Engenharia de São Carlos-Universidade de São Paulo, 2004 .

Área Interunidades: Bioengenharia.

Orientador: Prof. Dr. Nivaldo Antônio Parizotto.

Co-orientador: Prof. Dra. Cibele Marli Cação Paiva Gouvêa

1. Ultra-som terapêutico. 2. Reparo ósseo. 3. Inflamação. I. Título. 
Dedico este trabalho ao meu marido e filhos, alicerces e parceiros de cada sonho e vitória da minha vida. 


\section{AGRADECIMENTOS}

Em especial ao meu marido Ederson, que sempre acreditou no meu potencial. Aos meus filhos, Vanessa e Igor, origem e âncoras de toda minha força e determinação. À minha família, peço perdão pelos momentos de ausência.

Ao professor Nivaldo, meu orientador, pela confiança em mim depositada, pelo porto seguro que representa, sempre sereno, mesmo nas horas de dificuldades e por nortear este trabalho de forma tão significativa.

À Professora Cibele, minha co-orientadora, por tudo que aprendi e continuo aprendendo, pela dedicação e disponibilidade, verdadeiro marco na minha vida e pilar de sustentação deste trabalho.

À Josiane Marino e Anna Rachel Silveira Gomes, pelo compartilhamento de esperanças e vitórias, verdadeiras amigas de coração.

Aos professores do Departamento Interunidades em Bioengenharia de São Carlos pela acolhida e atenção a mim dispensada.

À Janete e a Melaine pela paciente ajuda sempre que foi necessária.

A todos que direta ou indiretamente contribuíram para a realização deste trabalho. 


\section{AGRADECIMENTO ESPECIAL}

À Vanessa Lira Leite, irmã de espírito, muito mais que uma colaboradora, foi uma verdadeira amiga e contribuiu definitivamente para a realização deste trabalho, meus sinceros agradecimentos. 
“O valor das coisas não está no tempo em que elas duram, mas na intensidade com que acontecem. Por isso existem momentos inesquecíveis, coisas inexplicáveis e pessoas incomparáveis". (autor desconhecido) 


\section{RESUMO}

\section{Estudo comparativo do efeito do ultra-som terapêutico de $1 \mathrm{MHz}$ com freqüência de repetição de pulso de $100 \mathrm{~Hz}$ e $16 \mathrm{~Hz}$ no reparo de osteotomia por escareação em tíbia de rato.}

O objetivo deste trabalho foi comparar o efeito do ultra-som terapêutico de $1 \mathrm{MHz}$, nas freqüências de repetição de pulso de $100 \mathrm{~Hz}$ e $16 \mathrm{~Hz}\left(0,5 \mathrm{~W} / \mathrm{cm}^{2} \mathrm{SATA}\right)$, no processo de reparo de tíbia após osteotomia experimental. Neste trabalho foram utilizados 40 ratos machos albinos Wistar, divididos em 4 grupos experimentais: referência, controle, tratados com ultra-som terapêutico de $100 \mathrm{~Hz}$ (UST100) e $16 \mathrm{~Hz}$ (UST16). Os animais foram submetidos à fratura cirúrgica por escareação e, após 24 h, iniciou-se o tratamento com ultra-som terapêutico, por 6 dias consecutivos, durante $3 \mathrm{~min}$ ao dia. No $7^{\circ}$ dia póscirúrgico foi realizada coleta de sangue através de punção cardíaca para quantificação dos níveis de fosfatase alcalina, em seguida os animais foram submetidos à eutanásia, a tíbia fraturada foi removida, radiografada e fixada para análise histológica. Para determinar a significância das diferenças observadas foi utilizada análise de variância (ANOVA). Os diâmetros da lesão da tíbia foram significativamente menores nos grupos UST100, UST16, respectivamente, em comparação ao grupo controle. O nível de fosfatase alcalina foi significativamente diferente nos grupos experimentais. A densidade de matriz óssea, fibroblastos, macrófagos, neutrófilos, linfócitos e vasos sangüíneos foram significativamente diferentes entre os grupos, indicando que o tratamento com ultra-som induziu o reparo ósseo. O tratamento com UST acelerou a fase aguda da recuperação óssea, 
sendo que, o UST com freqüência de repetição de pulso de $100 \mathrm{~Hz}$ demonstrou ser mais eficaz.

Palavras chave: ultra-som terapêutico; reparo ósseo; inflamação. 


\begin{abstract}
Comparative study of the $1 \mathrm{MHz}$ with pulse frequency repetition of $100 \mathrm{~Hz}$ and $16 \mathrm{~Hz}$ therapeutic ultrasound effect in rat tibia healing after osteotomy.
\end{abstract}

The aim of this work was to compare the $1 \mathrm{MHz}$ with pulse frequency repetition of $100 \mathrm{~Hz}$ and $16 \mathrm{~Hz}$ therapeutic ultrasound effect $\left(0.5 \mathrm{~W} / \mathrm{cm}^{2}\right.$ SATA $)$ in the repair process of the experimental tibia osteotomy. In this work we used 40 male albino Wistar rats divided into 4 experimental groups: reference; control; $100 \mathrm{~Hz}$ (UST100) and $16 \mathrm{~Hz}$ (UST16) therapeutic ultrasound-treated. The rats undergone bone surgical fracture and the ultrasound treatment started $24 \mathrm{~h}$ after the surgery, the treatment lasted for 6 days, during $3 \mathrm{~min}$ a day. The blood was sampled by cardiac punction for alkaline phosphatase level quantification at the $7^{\text {th }}$ day after surgery, than the animals were euthanized, the fractured tibia was removed, analyzed by radiography and fixed for histological analysis. The statistical significance of the analyzed parameters was tested with the ANOVA test. The diameter of the tibia lesion decreased significantly in the UST100 and UST16 groups, respectively, as compared to the control group. The blood alkaline phosphatase level was significantly different among experimental groups. The bone matrix, fibroblasts, macrophages, neutrophils, lymphocytes, and blood vessels densities were significantly different among experimental groups, indicating that the ultrasound treatment induced the bone repair. The UST treatment accelerated the acute phase of bone recovery and UST with pulse repetition frequency of $100 \mathrm{~Hz}$ was the most effective treatment.

Keywords: therapeutic ultrasound, bone repair, inflammation. 


\section{LISTA DE ABREVIAÇÕES}

UST Ultra-som terapêutico

ERA Área de radiação efetiva

SATA Spatial average temporal average - média espacial, média temporal

SATP Spatial average temporal peak - média espacial, pico temporal

$\mathrm{Hz} \quad$ Hertz - unidade de medida de freqüência

MHz Mega Hertz - unidade de medida de freqüência igual a um milhão de hertz

$\mathrm{kHz} \quad$ Kilohertz - unidade de medida de freqüência igual a mil Hertz

$\mathrm{W} / \mathrm{cm}^{2} \quad$ Wattes por centímetro quadrado - quantidade de energia em unidade de área por umidade de tempo

$\mathrm{mW} / \mathrm{cm}^{2} \quad$ Miliwattes por centímetro quadrado - quantidade de energia em unidade de área por unidade de tempo

W Wattes - quantidade de energia

rpm Rotações por minuto

nm Namometro

mA Miliamperes

$\mu \mathrm{m} \quad$ Micrômetro - unidade de medida utilizada em histologia $(1 \mu \mathrm{m}=0,001$

milimetro)

$\mu \mathrm{s} \quad$ Microsegundos

$\quad$ Microlitro

$\mathrm{mm}^{2} \quad$ Milímetro quadrado 
U/L Unidades por litro

$\mathrm{p} / \mathrm{v} \quad$ Peso por volume

HE Hematoxilina-eosina

PO Pós-operatório

TGF $\beta 1 \quad$ Fator de crescimento de transformador beta 1

TNF $\alpha \quad$ Fator de necrose tumoral alfa

bFGF Fator de crescimento de fibroblastos

VEGF Fator de crescimento do endotélio vascular

RNAm Acido ribonucléico mensageiro

IL $6 \quad$ Interleucina 6

IL 8 Interleucina 8

COX 2 Cicloxigenase 2

PCR Polymerase chain reaction - Reação em cadeia da polimerase 


\section{LISTA DE FIGURAS}

Figura 1 Atividade de fosfatase alcalina sérica 38

Figura 2 Diâmetro da lesão óssea $\quad 39$

Figura 3 Radiografia da tíbia de ratos aos 7 dias após a osteotomia 39

Figura 4 Fotomicrografia de corte longitudinal da tíbia do membro posterior esquerdo de rato corado com HE. A, referência: animal não lesado e $\mathbf{B}$, controle submetido a osteotomia por escareação

Figura 5 Fotomicrografia do local da osteotomia da tíbia de rato controle. CI, calo interno e $\mathbf{C E}$, calo externo

Figura 6 Fotomicrografia de corte longitudinal da tíbia de rato. A, tratado com ultrasom de $1 \mathrm{MHz}$ na modulação de pulso de $100 \mathrm{~Hz}$ e $\mathbf{B}$, tratado com ultra-som de $1 \mathrm{MHz}$ na modulação de pulso de $16 \mathrm{~Hz}$

Figura 7 Fotomicrografia do local da osteotomia da tíbia de rato do grupo UST100

Figura 8 Fotomicrografia do local da osteotomia da tíbia de rato do grupo 


\section{LISTA DE TABELAS}

Tabela 1 Densidade de matriz óssea

Tabela 3 Densidade de estruturas (fibroblastos, macrófagos, neutrófilos, linfócitos e vasos sanguíneos)

Tabela 2 Valores percentuais do aumento da densidade de matriz óssea

Tabela 4 Valores percentuais da densidade de fibroblastos, macrófagos, neutrófilos,

linfócitos e vasos sanguíneos 


\section{SUMÁRIO}

\section{RESUMO}

ABSTRACT

LISTA DE FIGURAS

LISTA DE TABELAS

LISTA DE ABREVIAÇÕES

1 INTRODUÇÃO 15

2 REVISÃO DA LITERATURA 17

$\begin{array}{ll}2.1 \text { TECIDO ÓSSEO } & 17\end{array}$

2.2 FRATURA ÓSSEA E REPARO 20

2.3 INDICADORES BIOQUÍMICOS DA REPARAÇÃO ÓSSEA 23

2.4 ULTRA-SOM TERAPÊUTICO 24

2.5 ULTRA-SOM TERAPÊUTICO E FRATURA ÓSSEA 26

3 MATERIAIS E METÓDOS 32

3.1 ANIMAIS DE EXPERIMENTAÇÃO 32

3.2 GRUPOS EXPERIMENTAIS 32

3.3 PROTOCOLO DE LESÃO ÓSSEA 33

3.4 TRATAMENTO COM ULTRA-SOM 34

3.5 DOSAGEM DE FOSFATASE ALCALINA SÉRICA 35

3.6 ANÁLISE RADIOLÓGICA 35

3.7 ANÁLISE MORFOLÓGICA 35

3.8 ANÁLISE ESTATÍSTICA 36 
4.1 ANÁLISE DE FOSFATASE ALCALINA

4.2 ANÁLISE RADIOLÓGICA

4.3 ANÁLISE MORFOLÓGICA

4.3.1 ANÁLISE HISTOLÓGICA

4.3.2 ANÁLISE MORFOMÉTRICA

5 DISCUSSÃO 


\section{INTRODUÇÃO}

O tecido ósseo é um tipo especializado de tecido conjuntivo formado por células e material intracelular calcificado, a matriz óssea, compostas por sais de cálcio e colágeno, além de outros componentes. É um dos tecidos mais rígidos e resistentes do corpo humano. Contudo, é freqüentemente lesado, ocorrendo fraturas que podem ser completas ou incompletas. A regeneração do tecido ósseo é determinada pela proliferação celular e deposição de sais de cálcio, que restabelecerão a arquitetura e funcionalidade e é dependente do estado nutricional do osso, da imobilização e de fatores bioquímicos e imunológicos. O processo biológico de reparo ósseo pode ocorrer lentamente (retardo de consolidação) ou não se desenvolver (pseudoartrose), resultando em deficiência ou incapacidade para o indivíduo. A taxa de formação ou degradação óssea pode ser estimada através de marcadores bioquímicos específicos, como a atividade de fosfatase alcalina e ácida séricas que indicam, respectivamente, a atividade de osteoblastos e osteoclastos (DOBLARÉ; GARCÍA; GOMÉZ, 2004).

Apesar dos crescentes avanços em algumas áreas sobre os procedimentos nas fraturas, o ortopedista pouco pode fazer para aumentar a velocidade de consolidação da fratura. Assim, terapias alternativas, que possam auxiliar na recuperação da fratura são 
muito importantes, pois podem minimizar o tempo de tratamento, bem como os custos, garantindo o retorno mais rápido às atividades de vida diárias.

O ultra-som terapêutico (UST) têm sido utilizado por mais de 50 anos, para o tratamento de tecidos ósseo, muscular e tendíneo lesados e diversos trabalhos têm demonstrado que o UST pulsado é eficiente na promoção da regeneração óssea (DYSON, 1987; DYSON; BROKES, 1983; DUARTE, 1983; CUNHA; PARIZOTTO; VIDAL, 2001; GOUVEA; VIEIRA; AMARAL, 1998).

Atualmente estão disponíveis no mercado equipamentos de UST, fabricados no Brasil, com freqüência de base de $1 \mathrm{MHz}$ e opções de modulação de pulso de $16 \mathrm{~Hz}$ e $100 \mathrm{~Hz}$. Contudo, não há trabalhos comparando a eficácia de ambas às modulações no reparo de fraturas ósseas.

Este trabalho teve por objetivo comparar o efeito do tratamento com UST de 1 $\mathrm{MHz}$, com repetições de pulso de $16 \mathrm{~Hz}$ e $100 \mathrm{~Hz}$, na recuperação da osteotomia experimental por defeito ósseo.

Assim, os objetivos específicos foram:

1. Avaliar o efeito do ultra-som através de análise radiográfica

2. Medir o nível de fosfatase alcalina no sangue dos animais.

3. Determinar a extensão da regeneração e/ou reparo por análise histológica quantitativa. 


\section{REVISÃO DE LITERATURA}

\subsection{Tecido ósseo}

O tecido ósseo é um dos mais resistentes e rígidos do corpo humano. Constituinte principal do esqueleto serve, de suporte para as partes moles e protege órgãos vitais tais como cérebro e coração; aloja e protege a medula óssea formadora das células do sangue; armazena e libera minerais; proporciona apoio aos músculos esqueléticos, transformando suas contrações em movimentos úteis e constitui um sistema de alavancas que amplia as forças geradas na contração muscular (GARDNER; GRAY; RAHILLY, 1988; JUNQUEIRA; CARNEIRO, 1999; FREEMONT, 1998; TORTORA; GRABOWSKI, 2002; DOBLARÉ; GARCÍA; GOMÉZ, 2004). É um tipo especializado de tecido conjuntivo em constante modificação, composto de células, de substância intercelular densa, a matriz óssea e de inúmeros vasos sanguíneos. As células são os osteoblastos, osteócitos e osteoclastos. Como não existe difusão de substâncias através da matriz calcificada do osso, a nutrição dos osteócitos depende de canalículos, que existem na matriz e que permitem a comunicação dos osteócitos com seus vizinhos, 
com a superfície interna e externa do osso e com os canais vasculares da matriz (GARDNER; GRAY; RAHILLY， 1988; JUNQUEIRA; CARNEIRO， 1999; DOBLARÉ; GARCÍA; GOMÉZ, 2004). As células osteogênicas são células tronco nãoespecializadas derivadas do mesênquima, o tecido a partir do qual todos os tecidos conjuntivos são formados. Encontram-se ao longo da parte interna do periósteo, no endósteo, nos canais e na medula óssea. Os osteoblastos são as células que sintetizam a parte orgânica da matriz óssea, colágeno tipo I, proteoglicanas e glicoproteínas. A disposição dos componentes inorgânicos no osso é dependente da presença de osteoblastos, que possuem prolongamentos citoplasmáticos que se fixam aos osteoblastos vizinhos. Quando aprisionados pela matriz óssea recém sintetizada passam a se chamar osteócitos. A matriz é depositada ao redor da célula e de seus prolongamentos formando as lacunas e os canalículos, respectivamente. Os osteócitos derivam-se dos osteoblastos envolvidos pela matriz óssea, entretanto não são capazes de secretar componentes da matriz. Mesmo situados na profundidade do tecido ósseo, estabelecem contato com as células vizinhas através dos canalículos, o que permite o fluxo intercelular de íons, nutrientes, metabólitos e pequenas moléculas, como hormônios que controlam o crescimento e desenvolvimento dos ossos. Os osteoclastos são células móveis, gigantes, derivados da fusão de até 50 monócitos do sangue circulante que após atravessar as paredes dos capilares ósseos, se concentram no endósteo. Têm ciclo de vida muito curto e representam um tipo de célula óssea transiente que é inativada e removida por processos de apoptose. Os osteoclastos secretam ácidos que diminuem o pH do osso, colagenase e outras enzimas lisossômicas que atacam a matriz e liberam cálcio. Por descalcificar e decompor o osteóide, o osteoclasto é capaz de escavar depressões arredondadas na superfície trabecular, subcortical e periostal cavando túneis na cortical óssea. Essa destruição da matriz óssea 
faz parte do desenvolvimento, crescimento, manutenção e reparo normais do osso (SIEBEL, 1999; FREEMONT, 1998; TORTORA; GRABOWSKI, 2002; DOBLARÉ; GARCÍA; GOMÉZ, 2004). A remodelagem óssea resulta do balanço entre estes dois tipos de células, osteoclastos e osteoblastos, responsáveis pela reabsorção e deposição óssea, respectivamente (CANCEDDA et al., 2003; LI et al., 2003).

As superfícies internas e externas dos ossos são recobertas por células osteogênicas e tecido conjuntivo, que formam o endósteo e o periósteo. Este revestimento é essencial para a manutenção do tecido, pois áreas de reabsorção óssea aparecem nos locais que perderam o revestimento conjuntivo ou a camada de osteoblastos. O periósteo é formado por tecido conjuntivo denso, muito fibroso em sua parte externa e mais celular e vascular na porção interna, junto ao tecido ósseo. As células do periósteo têm morfologia semelhante à dos fibroblastos, transformando-se muito facilmente em osteoblastos; têm importante papel no crescimento dos ossos e na recuperação de fraturas. $\mathrm{O}$ endósteo é geralmente constituído por uma camada de células osteogênicas achatadas, revestindo as cavidades do osso esponjoso, o canal medular, os canais de Havers e os de Volkmann. As principais funções de periósteo e do endósteo são nutrir o tecido ósseo, pois dos seus vasos partem ramos que penetram nos ossos pelos canais de Volkmann, além de servir de fonte de osteoblastos para o crescimento e reparação óssea (CARANO; FILVAROFF, 2003). O osso é ricamente vascularizado e os vasos sangüíneos penetram no osso a partir do periósteo e convergem em finas anastomoses em direção ao canal medular. A vascularização é um componente essencial para a homeostasia do tecido ósseo, visto que a descontinuação do suprimento sangüíneo pode causar necrose e prejudicar a cicatrização tecidual. Os nervos acompanham os vasos sanguíneos que suprem os ossos. A maioria dessas fibras é vasomotora e algumas são sensitivas. O periósteo é rico em nervos sensoriais, sendo este especialmente sensíveis á 
tração, tensão ou pressão. (CARANO; FILVAROFF, 2003; DOBLARÉ; GARCÍA; GOMÉZ, 2004).

\subsection{Fratura óssea e reparo}

A interrupção da continuidade de um osso longo seja traumática, patológica ou cirúrgica é seguida por uma seqüência histológica definida, destinada a preencher o espaço da lesão. Em geral, quando ocorre uma fratura há alguma laceração de periósteo e de endósteo podendo também haver deslocamento dos fragmentos. Os vasos sangüíneos do osso e dos tecidos moles adjacentes se rompem ocorrendo o extravasamento de sangue e, na seqüência há a formação de um coágulo ou hematoma dentro e ao redor do local da fratura. O fluxo sangüíneo cessa a uma distância variável de cada lado da linha de fratura e o osso imediatamente adjacente, por lesão indireta, torna-se necrótico. O tecido ósseo morto pode ser reconhecido pela presença de lacunas vazias (BUCKWALTER; CRUESS, 1993; CARANO; FILVAROFF, 2003; MUINCK; SIMONS, 2004; DOBLARÉ; GARCÍA; GOMÉZ, 2004). Mizuno et al. (1990) ao investigarem o papel do hematoma de fratura no processo de reparação, concluíram que o mesmo apresenta um inerente potencial osteogênico, e que por si só é capaz de induzir a formação óssea.

Nos estágios iniciais (1-2 dias após a fratura) há evidências histológicas de uma reação inflamatória aguda, onde são vistos inicialmente neutrófilos em abundância e, posteriormente, linfócitos e macrófagos. O coágulo sangüíneo ainda pode ser reconhecido entre as cavidades medulares e entre as extremidades fraturadas, atuando 
como um arcabouço de fibrina que facilita a migração das células de reparação (BUCKWALTER; CRUESS, 1993; GREENHALGH， 1998; FAURSCHOU; BORREGAARD, 2003; BARR; BARBE, 2004). Na medida em que a resposta inflamatória regride, o tecido necrosado e o exsudato são reabsorvidos, passando a haver a manifestação de um grau intenso de invasão celular e neovascularização, estes são os sinais iniciais de que a osteogênese está ocorrendo no local. Os eventos que se seguem são influenciados não só pelo grau de vascularização no local, como também pela quantidade de movimento livre permitido (CORMACK, 1996; STADELMANN; DIGENIS; TOBIN, 1998; DOBLARÉ; GARCÍA; GOMÉZ, 2004).

As células osteogênicas, ao se proliferarem, passam a levantar a camada fibrosa do periósteo afastando-a do osso. Ao mesmo tempo, as células osteogênicas do endósteo também se proliferam, mas não no mesmo ritmo da camada do periósteo. Desenvolve-se então um anel ou colar conjuntivo ao redor e entre as extremidades dos fragmentos, denominado calo. O calo que se forma ao redor das extremidades fraturadas é conhecido como o calo externo ou de fixação, enquanto aquele que se forma entre os fragmentos ósseos é denominado calo interno ou de ligação (CHAKKALAKAL et al. 1999; CORMACK, 1996; TUREK, 1991; DOBLARÉ; GARCÍA; GOMÉZ, 2004). Oni (1997), descreve que o calo ósseo é composto de tecidos contíguos, porém de tipos distintos quanto à sua origem e conseqüente arquitetura das fibras colágenas. Um tipo se desenvolve a partir do modelo cartilaginoso apresentando uma distribuição desorganizada das fibras, enquanto o outro se origina diretamente das células osteoprogenitoras que se diferenciam em osteoblastos.

Segundo Cormack (1996); Carano e Filvaroroff, (2003); Doblaré; García e Goméz, (2004), em uma fratura óssea humana não complicada, o calo é completamente formado ao final da segunda ou terceira semana. A formação de cartilagem no calo interno e 
externo tem uma existência temporária, sendo finalmente substituída por trabéculas de osso esponjoso (ossificação endocondral). A presença de grande quantidade de calo externo com alta proporção de cartilagem é característico de instabilidade do foco de fraturas ou imaturidade do tecido de reparo. Neste estágio o calo é uma massa fusiforme de osso esponjoso havendo a subseqüente conversão em osso cortical denso e o restabelecimento do contorno original do osso. O tecido ósseo imaturo passa a ser progressivamente substituído por tecido ósseo maduro, enquanto o processo osteogênico dentro da medula é reabsorvido e substituído pela medula hematopoiética e tecido gorduroso.

As trações e pressões exercidas sobre o osso durante a reparação da fratura causam a remodelação do calo ósseo e sua completa substituição por tecido ósseo lamelar. Deste modo, se a fratura estiver alinhada e as forças atuantes restauradas haverá a reconstrução progressiva e total do osso (BUCKWALTER; CRUESS, 1993; TUREK, 1991; DOBLARÉ; GARCÍA; GOMÉZ, 2004).

Em anos recentes, o mecanismo piezoelétrico recebeu grande atenção, especialmente com relação a sua possível função no crescimento e remodelagem dos tecidos conjuntivos, assim como na cura das fraturas dos ossos.

O efeito piezoelétrico no osso foi descrito por FUKADA e YASUDA (1957) ao demonstrarem que o osso desenvolve campos elétricos em sua superfície quando submetido à tensão mecânica. A piezoeletricidade óssea ocorre devido ao colágeno, pois mesmo o osso desmineralizado em solução ácida apresenta efeito piezoelétrico podendo gerar sinais elétricos depois de ter sofrido tensão mecânica, contribuindo para reparação óssea (BASSET; BACKER, 1962).

Charman (1990) aponta evidências comprovando que, tanto o osso como os demais tecidos conjuntivos geram correntes e gradientes de potencial quando mecanicamente 
deformados por forças externas como compressão, tração, arqueamento, cisalhamento e forças de rotação axial. Estas forças são criadas naturalmente nos tecidos e enormemente ampliadas durante atividades esportivas ou atividades laborais que geram potenciais sendo que os negativos relacionam-se à formação óssea (atividade osteoblástica) e potenciais positivos relacionam-se à reabsorção óssea (atividade osteoclástica). De acordo com a Lei de Wolff, potenciais e correntes gerados endogenamente agem como um sistema controle para as remodelações adaptativas do osso em resposta a sobrecarga (BUCKWALTER; CRUESS 1993).

\subsection{Indicadores bioquímicos da reparação óssea}

A taxa de formação ou degradação óssea pode ser estimada através de marcadores bioquímicos específicos. A atividade de fosfatase alcalina ou ácida séricas indica, respectivamente, a atividade de osteoblastos e osteoclastos. A medida de componentes da matriz óssea liberados na circulação pode também ser utilizada para a determinação da formação ou reabsorção óssea, como a determinação dos níveis de osteocalcina, produto gênico específico dos osteoblastos (GARNERO; DELMAS, 1988).

Os osteoblastos secretam grande quantidade de fosfatase alcalina quando estão depositando ativamente matriz óssea (GUYTON; HALL, 1997; HENTHORN et al., 1999; FREEMONT, 1998; IM et al., 2003). A fosfatase alcalina provavelmente aumenta a concentração local de fosfato inorgânico ou ativa as fibras colágenas de tal maneira que causa a deposição de sais de cálcio. Pelo fato da fosfatase alcalina difundir-se pelo 
sangue, o nível sanguíneo é considerado um bom indicador da taxa de formação do osso (GUYTON; HALL, 1997).

Em estudo prospectivo, Laurer et al. (2000) analisaram amostras de sangue humano coletado nas primeiras 24 h após lesão óssea. Esses autores avaliaram: trauma ósseo associado a lesão de tecidos moles; fratura diafisária; traumas múltiplos; fratura proximal de fêmur e fratura de quadril e/ou colocação de endoprótese. Todos os grupos apresentaram aumentos nos níveis de fosfatase alcalina, sendo que as fraturas diafisárias obtiveram os níveis mais elevados. O nível sérico da enzima fosfatase alcalina reflete a diferenciação osteoblástica durante o processo de reparo de fratura (FARLEY; STILTCOFFING, 2001).

\subsection{Ultra-som terapêutico}

O aparelho de ultra-som terapêutico (UST) consiste de um gerador que produz uma corrente alternada de alta freqüência. Para fisioterapia utilizam-se freqüências entre 0,5 e 5,0 MHz (LEHMANN; DE LAUTER, 1994; ter HAAR, 1987). Para tal, transdutores piezoelétricos são utilizados. Estes consistem em um disco de um material natural, como o quartzo, ou uma cerâmica sintética feita de uma mistura de sais complexos, tais como o zirconato e o titanato, os quais podem ser polarizados em processos de carga (WILLIANS, 1987). Esse elemento piezoelétrico transforma energia acústica em energia elétrica e seu reverso, energia elétrica em acústica (KANH, 1991; HEKKENBERG; OOSTERBAAN, 1985). A corrente alternada que alimenta o elemento piezoelétrico pode ser modulada criando diferentes modalidades de insonação: 
contínua e pulsada. Deste modo, a intensidade é também dependente do tempo (HEKKENBERG; OSTERBAAN, 1985).

O ultra-som terapêutico tem sido utilizado no restabelecimento das funções e promoção da cicatrização de tecidos musculares, tendinosos e ósseos lesados (CUNHA; PARIZOTTO; VIDAL, 2001; GOUVEA; VIEIRA; AMARAL, 1998; DUARTE, 1983; DUARTE; XAVIER, 1983). Desde a introdução deste recurso terapêutico, há mais de 5 décadas, as ações biológicas do ultra-som têm sido investigadas. Contudo, os efeitos mecânicos, térmicos e químicos do ultra-som ainda não estão completamente esclarecidos. Sua aplicação, entretanto, leva a inúmeros bioefeitos, que podem ser classificados em térmicos e não-térmicos (DYSON, 1987; KITCHEN; PARTRIDGE, 1990). Os efeitos considerados térmicos são aumento da elasticidade de estruturas que contém colágeno, diminuição da rigidez articular, diminuição da dor e do espasmo muscular e aumento do fluxo sangüíneo. Os efeitos não-térmicos induzem reações orgânicas, que geralmente se manifestam em nível vascular e tecidual (DYSON, 1987). Baker; Robertson e Duck (2001) consideram incorreto classificar separadamente os efeitos do UST em térmico (UST contínuo) e não-térmico (UST pulsado) porque os dois efeitos não estão totalmente separados. Sempre os efeitos não-térmicos serão acompanhados por um pouco de aquecimento devido à interação entre o UST e o tecido ser simultaneamente térmica e mecânica.

Tem sido proposto que em conseqüência das vibrações longitudinais características do ultra-som, um gradiente de pressão é desenvolvido nas células individuais. Como resultado desta variação de pressão, elementos da célula são obrigados a se moverem, ocorrendo, um movimento de micromassagem, que aumenta o metabolismo celular, o fluxo sangüíneo e o suprimento de oxigênio, produzindo alteração da permeabilidade da membrana celular e facilitando o fluxo de nutrientes (DYSON; SUCKLING, 1978). As 
ondas ultra-sônicas se propagam através dos tecidos e a absorção de radiação depende do coeficiente de absorção relativo ao conteúdo protéico dos tecidos, sendo que a absorção desta energia determina os efeitos biológicos (KITCHEN; PARTRIDGE, 1990).

\subsection{Ultra-som terapêutico e fratura óssea}

Considerando que a cicatrização do osso envolve processos gerais similares àqueles associados à cicatrização do tecido mole, supõe-se que o processo de reparação e/ou formação óssea possa ser igualmente estimulado pelo ultra-som terapêutico. Diversos autores evidenciaram, em estudos tanto experimentais quanto clínicos, aceleração e/ou potencialização da reparação óssea mediante o emprego do UST. A propagação do UST estabelece no tecido ósseo um campo de deformações elásticas associado a regiões de rarefação e compressão da onda de pressão. Tal campo desenvolve potenciais elétricos nos tecidos ósseos, determinados pelo efeito piezoelétrico e pela microestrutura do osso. Esta polarização faz com que os osteoblastos alterem seus potenciais de membrana permitindo um bombeamento de íons e a captação de nutrientes (ALBERTIN, 1983; SILVA, 1987; PILLA, 2002). Duarte e Xavier (1983) afirmam que a presença de cargas elétricas no osso é vital, não só para seu desenvolvimento, mas principalmente para o reparo em caso de fratura. No caso da estimulação ultra-sônica, essas cargas seriam produzidas no osso por meio do efeito piezoelétrico, pois o ultra-som pulsado atinge o tecido ósseo como uma sucessão de impulsos mecânicos, cada um deles resultando em um sinal elétrico como resposta do osso. Pilla (2002) comparou se a indução óssea 
promovida pelo UST é similar à promovida por correntes elétricas de pulso assimétrico analisando sinais biofísicos e concluiu que ambas geram potenciais de superfície, contudo as geradas pelo UST parecem ser mais eficientes.

A diversidade de modelos experimentais descritas na metanálise realizada por Busse et al. (2002) que apresentam freqüências variadas (1 a $3 \mathrm{MHz}$ ), diferentes intensidades, tempos de aplicação, diferentes tamanhos de ERA (área de radiação efetiva) e áreas de lesão dificultam interpretação e associação das informações obtidas sobre os efeitos fisiológicos do UST aplicadas ao tecido ósseo e a escolha do melhor modo de tratamento para fraturas ósseas. No entanto consideram que o tratamento das fraturas com UST pode reduzir o tempo de reparo e, conseqüentemente, os custos financeiros e sociais relacionados ao retardo de consolidação ou não-união óssea.

A escolha de diferentes freqüências (1 a $3 \mathrm{MHz})$ se deve à atenuação que a energia acústica sofre ao passar pelos tecidos. Freqüências menores atingem tecidos mais profundos (1 MHz e 1,5 MHz) enquanto que as maiores (3 MHz) são mais superficiais (DYSON, 1987; ter HAAR, 1999; REHER et al., 1997).

Vários autores investigaram a ação do UST de baixa intensidade na freqüência 1,5 $\mathrm{MHz}\left(30 \mathrm{~mW} / \mathrm{cm}^{2} \mathrm{SATA}\right)$, com intervalos de pulsos de $200 \mu \mathrm{s}$, freqüência de repetição de $1 \mathrm{kHz}$ e ciclo de trabalho de $20 \%$ no reparo das fraturas. Utilizando tais parâmetros, Duarte (1983) demonstrou a aceleração do processo de reparo ósseo em fraturas (osteotomia bilateral) de fíbulas e córtex de fêmures de coelhos. O tempo de aplicação foi de $15 \mathrm{~min} /$ dia e o tratamento variou de 4 a 18 dias. Foram realizadas avaliações qualitativas (radiológica e histológica) e quantitativas (fotografia e mensuração da área do calo). Os resultados demonstram que o ultra-som pode induzir alterações no osso fraturado rapidamente, nos primeiros 10 a 12 dias de estimulação, as quais se estabilizam após este período. Na análise histológica este autor observou que, enquanto 
os cortes histológicos dos ossos não-tratados apresentavam áreas de necrose, os ossos tratados continham osteoblastos, indicativo de reparo tecidual. Nos radiogramas foi possível observar claramente a formação de calo ósseo, mais rapidamente nos membros tratados, quando comparados aos controles. Quanto à área de calo ósseo, esta se apresentou maior nas fraturas estimuladas com ultra-som. Estes resultados sugerem que, com parâmetros adequados, a energia ultra-sônica pode acelerar a cura de uma fratura.

Um estudo de caso relata que paciente jovem, com fratura de hamato por acidente com motocicleta após 4 meses de lesão apresentava ao exame físico, dor e dificuldades de movimentação. Ao raio X e a tomografia computadorizada ficou comprovado a nãounião óssea. O local da fratura foi exposto a ultra-som durante $20 \mathrm{~min}$, diariamente durante 4,5 meses. Após o tratamento novos exames foram realizados e comprovaram a união e consolidação óssea (FUJIOKA et al., 2000). Também Tanzer; Kantor e Bobyn (2000) investigaram através de microscopia eletrônica, o efeito do UST de baixa intensidade sobre a osteogênese em modelo experimental de lesões ósseas cirúrgicas, com implante intramedular feitas em ulna de cães. O tratamento foi de 20 min diários por 6 semanas. Esses autores evidenciaram nos grupos tratados, um aumento de volume de fração óssea em desenvolvimento de 8,0 a 18,1\%, comparado ao membro contralateral não-tratado (controle). Nestes mesmos parâmetros, Zhang et al. (2002) realizaram um estudo experimental sobre o efeito do UST de baixa intensidade na produção de matriz óssea por condrócitos, nos diferentes estágios de diferenciação celular do esterno de embriões de galinha com 16 dias de vida, através de análise histológica e imunoistoquímica. Duas porções diferentes do esterno foram analisadas, na porção superior onde predomina ossificação endocondral e na porção distal, de cartilagem hialina. Os esternos foram dissecados e colocados em meio de cultura separadamente. A insonação começou $24 \mathrm{~h}$ depois e foi realizada por $20 \mathrm{~min} / \mathrm{dia}$. A 
produção de colágeno tipo II, tipo X e agrecanas demonstraram ser estatisticamente significativas maiores nas culturas das porções proximais de condrócitos tratadas com UST quando comparadas com o controle, indicando importante atuação no reparo destes tecidos. A insonação de fêmures de coelhos em diferentes níveis de potências acústicas $(26,39,52$ e $65 \mathrm{~W}$ por $10 \mathrm{~s})$ por $4 \mathrm{~h}, 14$ e 28 dias, demonstrou que altas doses (39 a 65 W) de insonação resultam lesões em térmicas no sistema músculo esquelético com presença de necrose, principalmente se utilizado por extensos períodos (SMITH et al., 2001). Estudos experimentais de osseointegração de implantes dentais de titânio com implantados em tíbia de coelho mostraram diferença estatisticamente significativa, apresentando áreas ao redor e dentro das espiras com uma maior quantidade de osso calcificado nos implantes tratados com ultra-som de baixa intensidade por $20 \mathrm{~min}$ diários, demonstrando indução e aumento de massa óssea local (COLUCCI, 2002). Entretanto, os efeitos do ultra-som de 1,5 MHz, intensidade de $30 \mathrm{~mW} / \mathrm{cm}^{2}$ (SATA) pulsado a $200 \mu \mathrm{s}$, aplicado por $20 \mathrm{~min} /$ dia não apresentaram diferenças estatisticamente significativas do controle em modelo experimental de lesões ósseas esféricas $(0,5 \mathrm{~mm}$ de diâmetro) em cortical de mandíbula de ratos (SCHORTINGHUIS; RAGHOEBAR; STEGENGA, 2004b).

Outras freqüências têm demonstrado eficácia em acelerar o reparo e/ou regeneração óssea. Faganello e Carvalho (1999) compararam os efeitos do UST $1 \mathrm{MHz}$ contínuo com $0,3 \mathrm{~W} / \mathrm{cm}^{2}$ de intensidade e UST $1 \mathrm{MHz}$ pulsado a $20 \%$ e intensidade de 0,3 $\mathrm{W} / \mathrm{cm}^{2}$ (SATA) sobre fraturas experimentais em ratas osteopênicas. Os resultados das avaliações demonstraram que, com o regime contínuo houve bloqueio da reparação óssea, já em regime pulsado houve a formação de calo proeminente no animal tratado quando comparado ao grupo controle. Li et al. (2003) investigaram os efeitos do UST 1 $\mathrm{MHz}$ pulsado a $20 \%$ com modulação de pulso a $100 \mathrm{~Hz}$ na intensidade de $0,6 \mathrm{~W} / \mathrm{cm}^{2}$ 
(SATP) para estimular a atividade osteoblástica em cultura de células ósseas da calvária de ratos. O UST foi aplicado por $15 \mathrm{~min} /$ dia em amostras com 1, 2, 3 e 4 dias de tratamento. Os resultados demonstram que a atividade mitocondrial dos osteoblastos aumentou significativamente desde a primeira insonação e permaneceu aumentando nos dias subseqüentes. As amostras apresentaram aumento significativo de secreção de TGF ß1, indicativo de atividade osteoblástica e diminuição média da secreção de IL-6 e $\mathrm{TNF} \alpha$ precursores da diferenciação de osteoclastos. Estes resultados sugerem que o UST pode não só estimular a produção óssea como diminuir uma possível reabsorção. Também Yang e Park (2001) evidenciaram a aceleração da consolidação óssea em estudo radiológico do calo ósseo de fraturas experimentais em ulna de cães tratadas com UST $1 \mathrm{MHz}$, pulsado $(200 \mu \mathrm{s})$, intensidade de $0,05 \mathrm{~W} / \mathrm{cm}^{2}$ (SATA) aplicados $15 \mathrm{~min}$ por 6 dias consecutivos. Os autores comparam uma série de radiografias um, três e cinco meses após a lesão e os resultados sugerem que o tratamento com UST acelerou o processo de neoformação óssea e diminuiu a incidência de não-união deste modelo de fratura quando comparados ao grupo controle e ainda que UST parece continuar agindo mesmo depois de prolongados períodos pós-tratamento. Guerino et al. (1997) em estudo experimental aplicaram UST $1 \mathrm{MHz}$ pulsado, $0,2 \mathrm{~W} / \mathrm{cm}^{2}$ de intensidade sobre osteotomia por escareação em tíbia de rato. O tratamento se iniciou 24 h após a cirurgia, por 5 min durante 30 dias. Foram realizados testes de resistência máxima de flexão, fecha de ruptura e rigidez flexural nas tíbias removidas. Os resultados não apresentaram diferenças estatisticamente significativas entre o controle e o tratado. Mesmo assim, os autores afirmam que o UST parece melhorar a rigidez óssea quando comparados ao controle. Sun et al. (2001) investigaram os efeitos do UST $1 \mathrm{MHz}$ pulsado na intensidade de $0,068 \mathrm{~W} / \mathrm{cm}^{2}$ em cultura de células ósseas da calvária de ratos. As amostras ficaram expostas ao UST por $20 \mathrm{~min} /$ dia. O inicio da aplicação foi do $4^{\circ}$ ao $10^{\circ}$ 
dia após o inicio da cultura. Após a insonação a contagem celular demonstrou aumento de osteoblastos e diminuição significativa de osteoclastos. O nível de fosfatase alcalina obteve valor médio aumentado aos 7 dias e o TNF $\alpha$ diminuiu $474 \%$ em média no $10^{\circ}$ dia quando comparados ao controle. Estes resultados indicam que o UST pode estimular o processo de reparo após lesão óssea. Reher et al. (1997) investigaram os efeitos do UST $3 \mathrm{MHz}$ estimulando in vitro, culturas de células ósseas provenientes de calvária de ratos com cinco dias de vida. Os parâmetros utilizados para o UST foram: contínuo e pulsado $1: 4$ ( $2 \mathrm{~ms}$ on e $8 \mathrm{~ms}$ off) nas intensidades 0,$1 ; 0,25 ; 0,5 ; 0,75 ; 1,0$; e $2,0 \mathrm{~W} / \mathrm{cm}^{2}$ (SATA) por 5 min. Os resultados obtidos sugerem que o UST em baixas intensidades (entre 0,1 e $0,5 \mathrm{~W} / \mathrm{cm}^{2}$ ) estimula de forma estatisticamente significativa a síntese de proteínas da matriz óssea (colágenas e não-colagenosas) e que altas intensidades $(0,75$ a $2 \mathrm{~W} / \mathrm{cm}^{2}$ ) inibem a produção das mesmas quando comparadas ao controle. Sugerem ainda que os mecanismos não-térmicos são os responsáveis pelo estímulo na produção dessas proteínas. Estes resultados parecem refletir os resultados clínicos obtidos no tratamento de fraturas e osteoradionecrose usando UST em baixas intensidades $(0,1$ W/cm² SATA). Reher et al. (1999) também compararam a indução de síntese de fatores angiogênicos promovidos pelos UST $1 \mathrm{MHz}$, pulsado 1:4 por $5 \mathrm{~min}$, em quatro intensidades $(0,1 ; 0,4 ; 0,7$ e 1,0 W/cm² SATA) e UST 45 kHz “ondas longas", contínuo por 5 min também em quatro intensidades $\left(5 ; 15 ; 30\right.$ e $\left.50 \mathrm{mWcm}^{2} \mathrm{SATA}\right)$, numa área média de 2-3 $\mathrm{cm}^{2}$, em cultura de células humanas. Aplicaram ultra-som em osteoblastos mandibulares, fibroblastos gengivais e monócitos do sangue. Os autores observaram aumento estatisticamente significativo de IL-8 (interleucina 8) e bFGF (fator de crescimento dos fibroblastos) nos fibroblastos estimulados e VEFG (fator de crescimento de endotélio vascular) em todos os tipos de células estimulados quando comparados ao controle. 


\section{MATERIAIS E MÉTODOS}

\subsection{Animais de experimentação}

Foram utilizados 40 ratos albinos machos Wistar com peso corporal de $270 \pm 20 \mathrm{~g}$ e cerca de 100 dias de vida. Os animais provenientes do Biotério da Efoa/Ceufe (Escola de Farmácia e Odontologia de Alfenas/Centro Universitário Federal) foram mantidos em caixas de polietileno (4 animais por caixa), em ambiente higienizado com água e ração comercial à vontade e iluminação com ciclos de 12 h (12 h com luz e 12 h no escuro).

\subsection{Grupos experimentais}

Os animais foram divididos aleatoriamente em 4 grupos de 10 animais cada: Referência, os animais não sofreram lesão nem tratamento com ultra-som terapêutico 
(UST); Controle, os animais sofreram lesão óssea e não foram tratados com UST; UST100, sofreram lesão óssea e foram tratados com UST com modulação de pulso de 100 Hz; UST16, sofreram lesão óssea e foram tratados com UST com modulação de pulso de $16 \mathrm{~Hz}$.

\subsection{Protocolo de lesão óssea}

Utilizou-se o modelo de osteotomia ou defeito ósseo (BARUSHKA; YAAKOBI; ORON, 1995; YAAKOBI; MALTZ; ORON, 1996; FREITAS; BARANAUSKAS; CRUZ-HÖFLING, 2000; MARINO, 2003), promovendo-se lesões ósseas esféricas de dimensões padronizadas, na cortical da tíbia de ratos, com a utilização de uma broca odontológica.

Os animais foram anestesiados com cetamina $(95 \mathrm{mg} / \mathrm{kg})$ e xilazina a $2 \%(12 \mathrm{mg} / \mathrm{kg})$, por via intraperitonial. A pele sobre a região ântero-medial da tíbia do membro posterior esquerdo foi tricotomizada. Em seguida, o animal foi mantido na posição supino, com o membro eleito em rotação externa de quadril e tríplice flexão (quadril/joelho/tornozelo). Com a utilização de um paquímetro digital, posicionado a partir da interlinha articular do joelho até o maléolo medial, foi verificado o comprimento total da tíbia, do qual foi calculado o valor do terço proximal. Após assepsia local, foi realizada uma incisão sobre a pele no local correspondente ao terço proximal da face medial da tíbia, a fáscia miotendínea da região foi recortada e após nova certificação do valor correspondente ao terço proximal, foi realizada osteotomia mecânica por escareação, utilizando-se uma broca de aço comum para contra-ângulo, cilíndrica, \# 559 (Maillefer - Suiça), acionada 
por motor com rotação de $13.700 \mathrm{rpm}$. Em um único movimento a mesma foi introduzida a $90^{\circ}$ em relação ao eixo longitudinal, no centro do osso cortical da face medial da tíbia (região diafisária), de modo a penetrar o osso cortical e lesar o trabeculado do canal medular, promovendo um defeito ósseo com o diâmetro de 1,5 mm. A seguir a pele foi suturada com fío não-absorvível e feita à limpeza local, não havendo posteriormente nenhum tipo de imobilização do segmento. Não foram utilizados antibióticos.

\subsection{Tratamento com ultra-som}

Antes do início do tratamento o equipamento de UST foi aferido no Departamento de Bioengenharia da Universidade de São Paulo (USP) - Campus de São Carlos. Os animais foram tratados por 5 dias consecutivos, durante 3 min com aparelho BIOSET, modelo Sonacel, com freqüência de $1 \mathrm{MHz}$, intensidade de $0,5 \mathrm{~W} / \mathrm{cm}^{2}$ (SATA), ciclo de trabalho de $20 \%$, ERA de 0,5 e freqüência modulada de pulso de 100 e $16 \mathrm{~Hz}$. O tratamento teve início 24 h após a cirurgia e os animais foram submetidos a eutanásia 7 dias após a cirurgia. 


\subsection{Dosagem de fosfatase alcalina sérica}

Foram determinados os níveis de fosfatase alcalina sérica, através de kit diagnóstico Analisa, no soro dos animais de todos os grupos experimentais. As análises foram realizadas 7 dias após a indução da osteotomia. Para isso foram coletados $300 \mu \mathrm{l}$ de sangue por punção cardíaca. Depois da coagulação, o soro foi separado por centrifugação em tubos eppendorf a $1.000 \mathrm{~g}$. A atividade enzimática foi determinada utilizando-se $25 \mu$ de soro e a absorbância foi determinada a $590 \mathrm{~nm}$.

\subsection{Análise radiológica}

A tíbia de todos os animais foi radiografada com um aparelho de raio-X odontológico de $50 \mathrm{kV} / 10 \mathrm{~mA}$. A seguir o diâmetro da osteotomia foi medido com paquímetro digital.

\subsection{Análise morfológica}

A tíbia dos animais foi fixada por $24 \mathrm{~h}$ em formol:ácido acético:etanol 80\% $(1: 2: 8,5)$ e, então, transferida para solução descalcificante, contendo EDTA a 5\% (p/v), que foi substituída a cada 2 dias. O osso permaneceu nesta solução por aproximadamente um 
mês. A seguir a tíbia foi seccionada longitudinalmente e processada tecnicamente com inclusão em parafina e microtomia da face medular, com $5 \mu \mathrm{m}$ de espessura. Os cortes foram corados com hematoxilina-eosina.

Foram determinados as densidades nos planos superficial e médio de matriz óssea de: linfócitos, macrófagos, neutrófilos, fibroblastos e vasos sangüíneos por morfometria, em área teste de $0,0625 \mathrm{~mm}^{2}$. Utilizou-se um sistema de análise de imagem por vídeomicroscopia, com auxílio de microscópio ótico acoplado a uma câmara de vídeo e a um monitor. Foram analisados 11 campos microscópicos aleatórios para cada grupo experimental.

\subsection{Análise estatística}

Foram determinadas as médias e desvios padrão e as diferenças entre os parâmetros analisados foram determinadas pelo teste ANOVA, seguido do pós-teste de comparação múltipla de Tukey-Kramer, quando $P<0,05$. 


\section{RESULTADOS}

\subsection{Análise de fosfatase alcalina}

Os níveis de fosfatase alcalina foram significativamente $\left(P<10^{-7}\right)$ diferentes nos

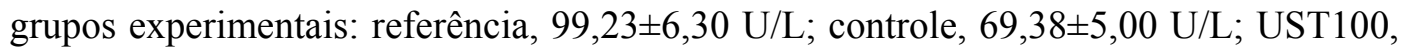
$120,86 \pm 8,19 \mathrm{U} / \mathrm{L}$ e UST16, $128,72 \pm 7,44$. Os animais submetidos ao tratamento com ultra-som apresentaram níveis séricos mais elevados da enzima fosfatase alcalina. Os animais do grupo UST100 restabeleceram mais rapidamente os níveis basais desta enzima (Fig. 1). 


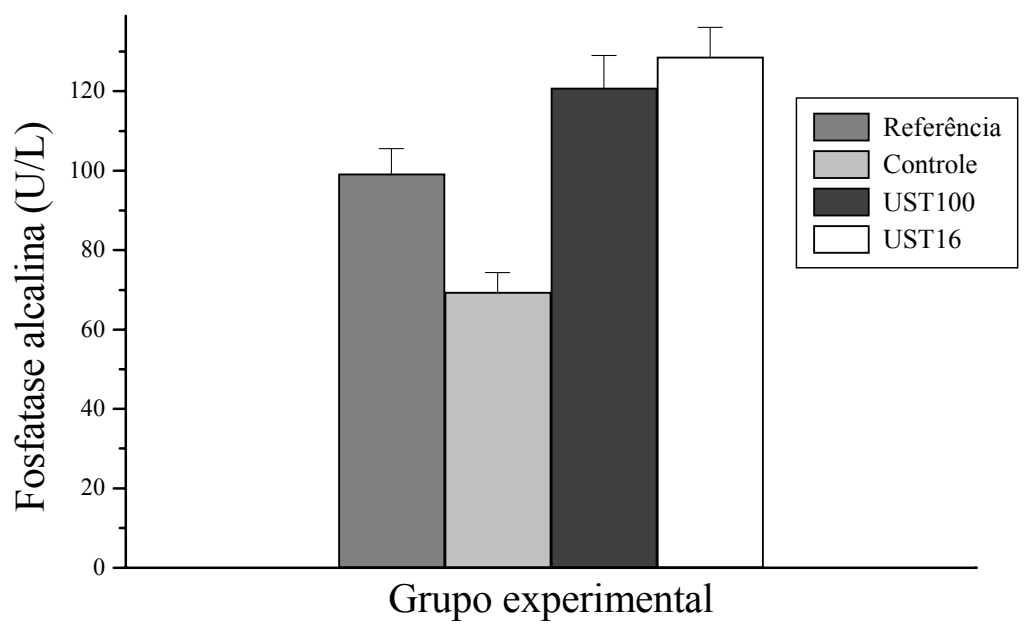

Figura 1. Atividade de fosfatase alcalina sérica (U/L) dos grupos referência ( $\square)$, controle ( $\square$ ), UST100 (animais tratados com ultra-som terapêutico na freqüência de 100 Hz, घ) e UST16 (animais tratados com ultra-som terapêutico na freqüência de 16 Hz, $\square)$.

\subsection{Análise radiológica}

Nas análises foram observadas diferenças radiológicas significativas $\left(P<10^{-6}\right)$ nos diâmetros do defeito ósseo dos animais controle e tratado (Fig. 2 e 3). Os diâmetros da

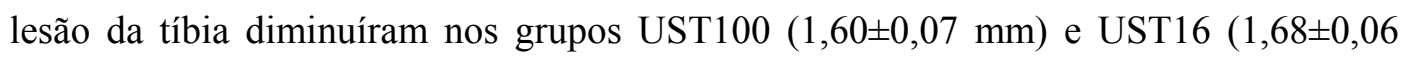
$\mathrm{mm})$, quando comparados ao controle $(1,93 \pm 0,09 \mathrm{~mm})$. 


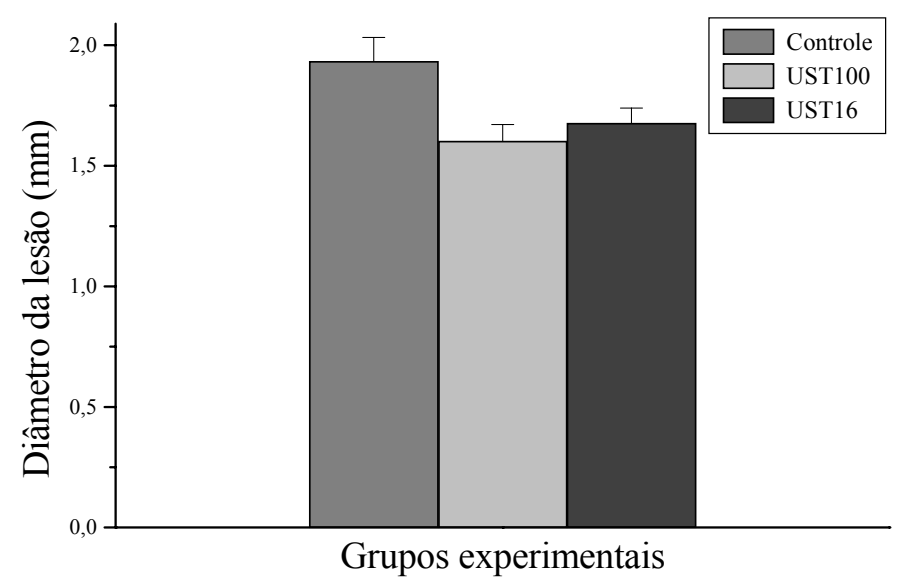

Figura 2. Diâmetro da lesão óssea nos grupos controle ( $\square$ ), UST100 (animais tratados com ultra-som terapêutico na freqüência de $100 \mathrm{~Hz}, \square$ ) e UST16 (animais tratados com ultra-som terapêutico na freqüência de $16 \mathrm{~Hz}, \mathbf{\square})$.

A

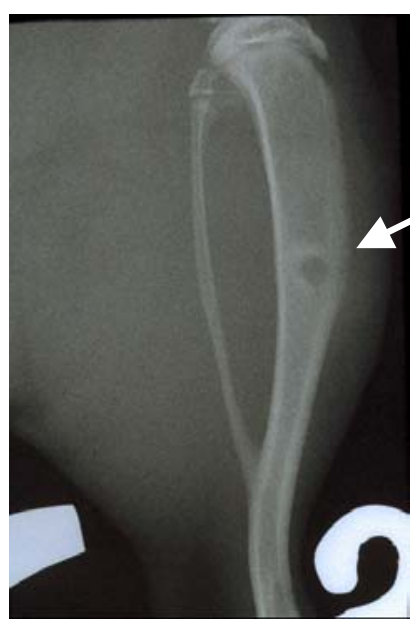

B

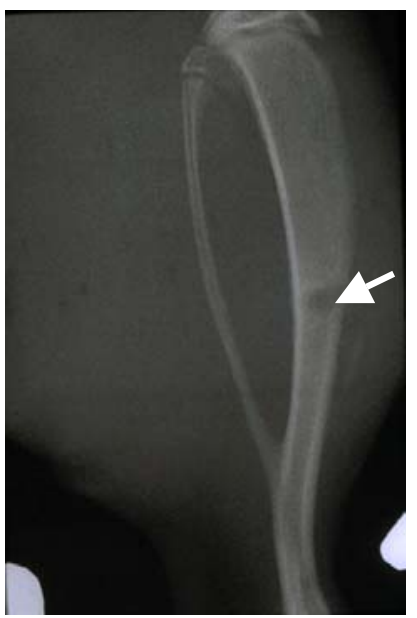

C

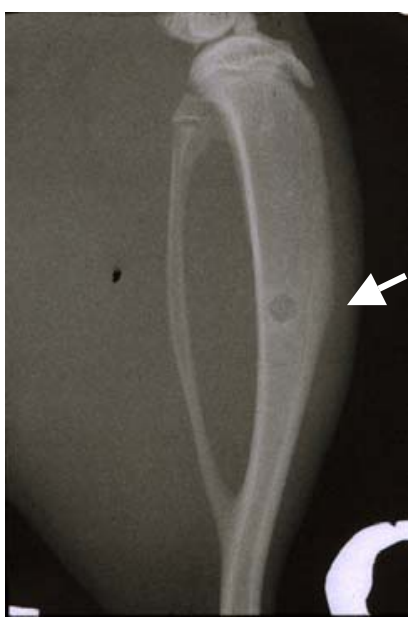

Figura 3. Radiografia da tíbia de ratos aos 7 dias após a osteotomia: A, controle; B, tratado com ultra-som de $1 \mathrm{MHz}$ na modulação de pulso de $100 \mathrm{~Hz}$ e $\mathbf{C}$, na modulação de pulso de $16 \mathrm{~Hz}$. 


\subsection{Análise morfológica}

A análise morfológica das tíbias lesadas revelou duas regiões ou zonas celulares distintas no sítio da lesão, observadas em todos os grupos experimentais estudados (Fig. 4 e 5). Essas regiões ou zonas foram denominadas de região média - calo interno (CI) e região superficial - calo externo (CE).

\subsubsection{Análise histológica}

A análise histológica demonstrou diferenças do padrão histológico nos diferentes grupos experimentais, bem como nas regiões superficial (CE) e na média (CI) de um mesmo grupo experimental (Fig. 4). Os tratamentos com freqüência modulada de pulso de $100 \mathrm{~Hz}$ e $16 \mathrm{~Hz}$ proporcionaram respostas diferentes. No grupo controle os cortes histológicos mostram tecido ósseo maduro com estrutura lamelar preservada, notandose lesão de descontinuidade em uma das faces corticais. Nota-se tecido ósseo neoformado predominante na porção distal da área de descontinuidade (ossificação endocondral) ocupando cerca da metade da distância intercortical. A metade proximal à lesão é constituída por cartilagem de revestimento neoformada, com áreas de diferenciação osteogênicas esparsas (ossificação endocondral) (Fig. 4B). A Fig. 5CI mostra o local de lesão, apresenta um mesclado de infiltrado inflamatório contendo macrófagos, neutrófilos e linfócitos entremeados por fibroblastos e matriz óssea. A Fig. 
5CE mostra o local de lesão com presença do mesmo infiltrado inflamatório e predomínio de fibroblastos formando tecido conjuntivo no grupo controle.

No grupo UST100 os cortes histológicos mostram tecido ósseo maduro com estrutura lamelar preservada, notando-se lesão de descontinuidade em uma das faces corticais com área parcialmente reconstituída. Nota-se espaço intercortical preenchido de tecido ósseo neoformado que se estende até a camada cortical distal preenchendo o espaço medular ósseo nesta região e permeando o tecido ósseo nota-se tecido conjuntivo frouxo vascularizado (Fig. 6A). O grupo UST16 apresenta aspecto histológico similar ao UST100. Os cortes histológicos mostram tecido ósseo maduro com estrutura lamelar preservada, neste grupo em todos os cortes nota-se lesão de descontinuidade em uma das faces corticais. Nota-se espaço intercortical preenchido de tecido ósseo neoformado que se estende até a camada cortical distal preenchendo o espaço medular ósseo nesta região e permeando o tecido ósseo nota-se tecido conjuntivo frouxo vascularizado. (Fig.6B).

Na região do CI no grupo UST100 (Fig. 7CI) nota-se um aumento na área de ossificação e permeando o tecido ósseo notam-se tecido conjuntivo frouxo. No calo externo (Fig. 7CE) nota-se fibroblastos dispostos de forma mais alinhada sugerindo que o UST com pulso modulado a $100 \mathrm{~Hz}$ favorece a organização tecidual. Já no grupo UST16 a região do calo interno (Fig. 8CI) mostra menor distribuição de matriz óssea, presença de células inflamatórias (linfócitos e macrófagos) e vasos sangüíneos. No calo externo (Fig. 8CE) o aspecto desorganizado permanece, a presença de células inflamatórias, especialmente linfócitos indicam provável atraso na regeneração quando comparados ao grupo UST100. 
$\mathbf{A}$
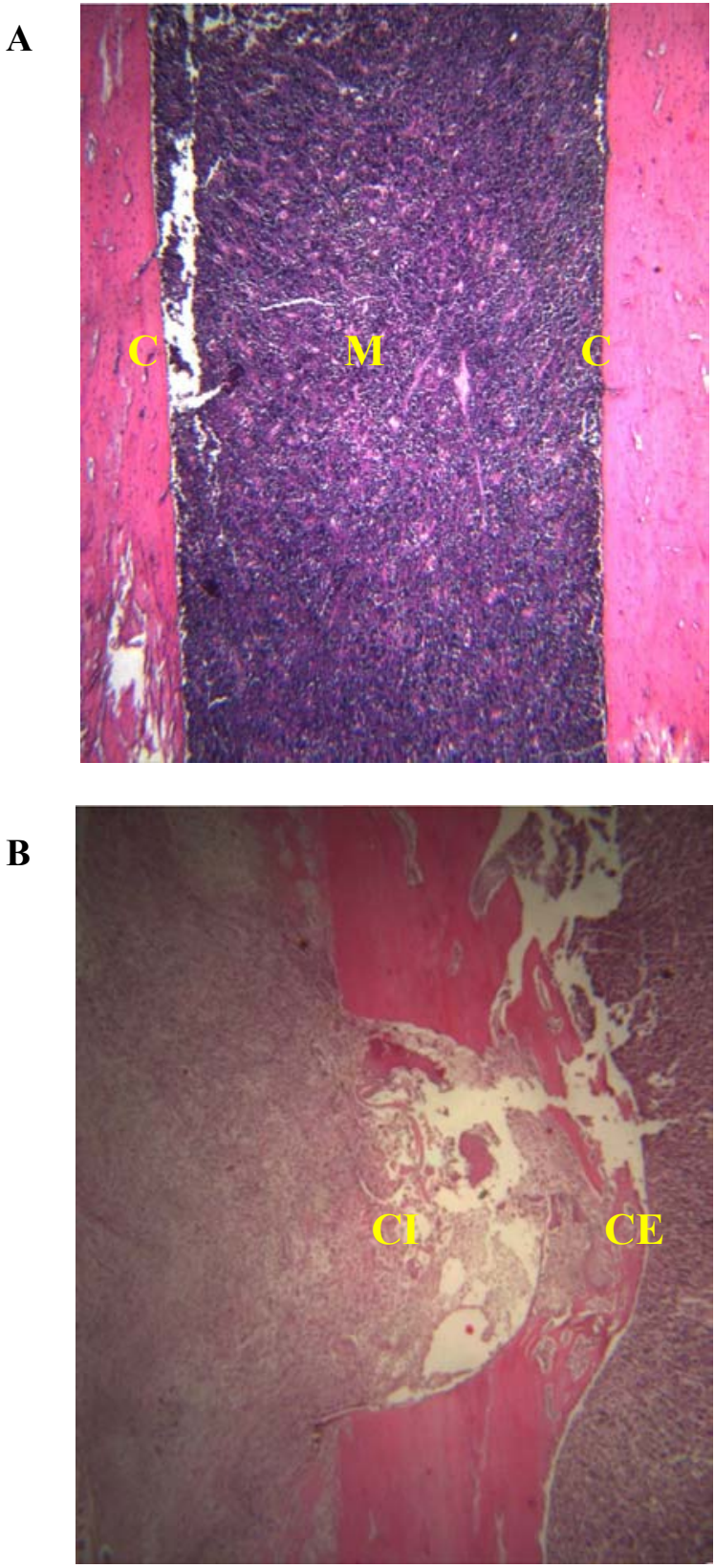

Figura 4. Fotomicrografia de corte longitudinal da tíbia do membro posterior esquerdo de rato corado com HE. A, referência: animal não lesado, onde se visualizam as regiões corticais (C) e medular (M) e B, controle submetido a osteotomia por escareação. Denotam-se nas regiões interna (CI) e externa (CE) a cortical lesada envolvidas por infiltrado inflamatório (IF) e visualização de cartilagem de revestimento (CR) e tecido ósseo neoformado (TO) relacionadas ao processo de reparo /e ou regeneração óssea. Aum. 50x. 

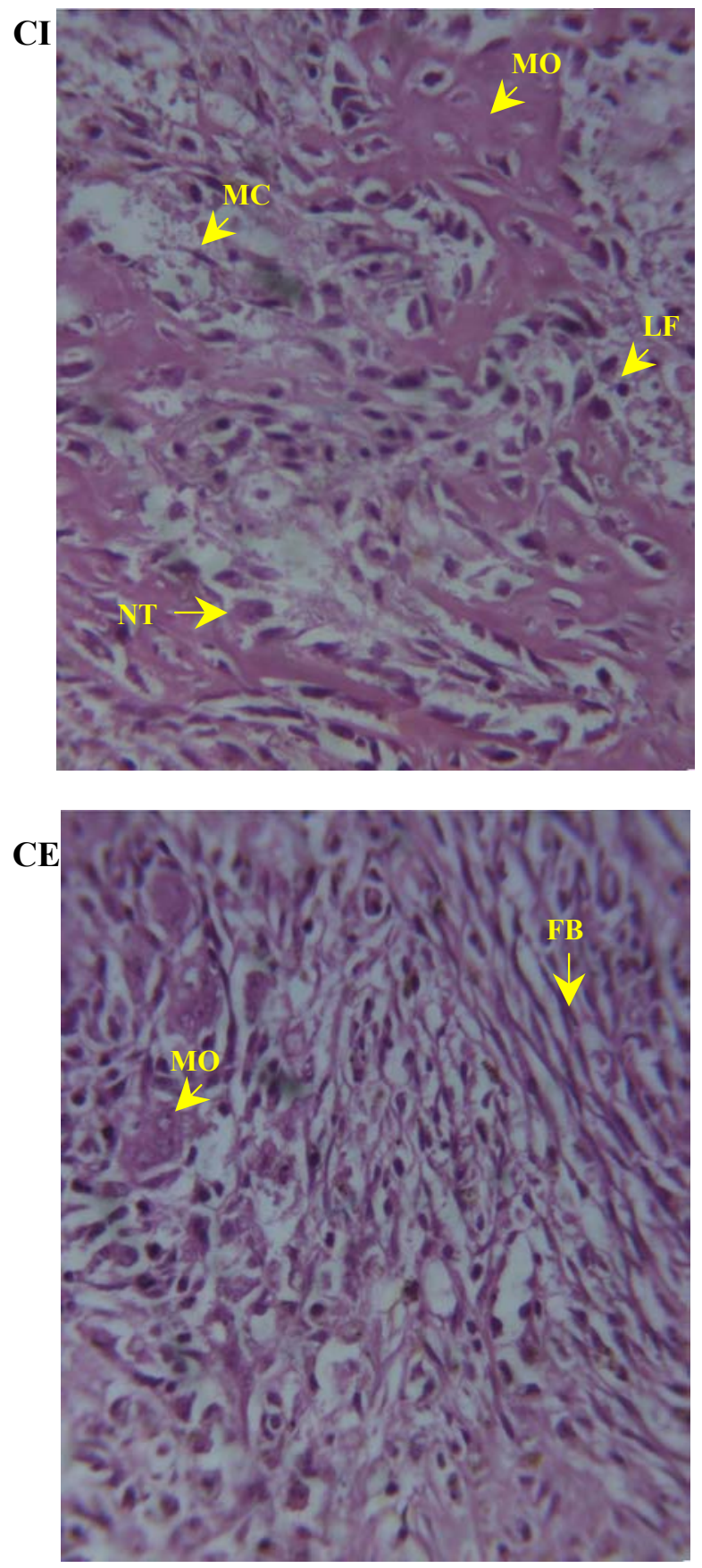

Figura 5. Fotomicrografia do local da osteotomia da tíbia de rato controle, corado com HE. CI, calo interno apresentando um mesclado de infiltrado inflamatório contendo macrófagos (MC), neutrófilos (NT) e linfócitos (LF) entremeados por fibroblastos (FB) e matriz óssea (MO); e CE, calo externo com presença do mesmo infiltrado. 

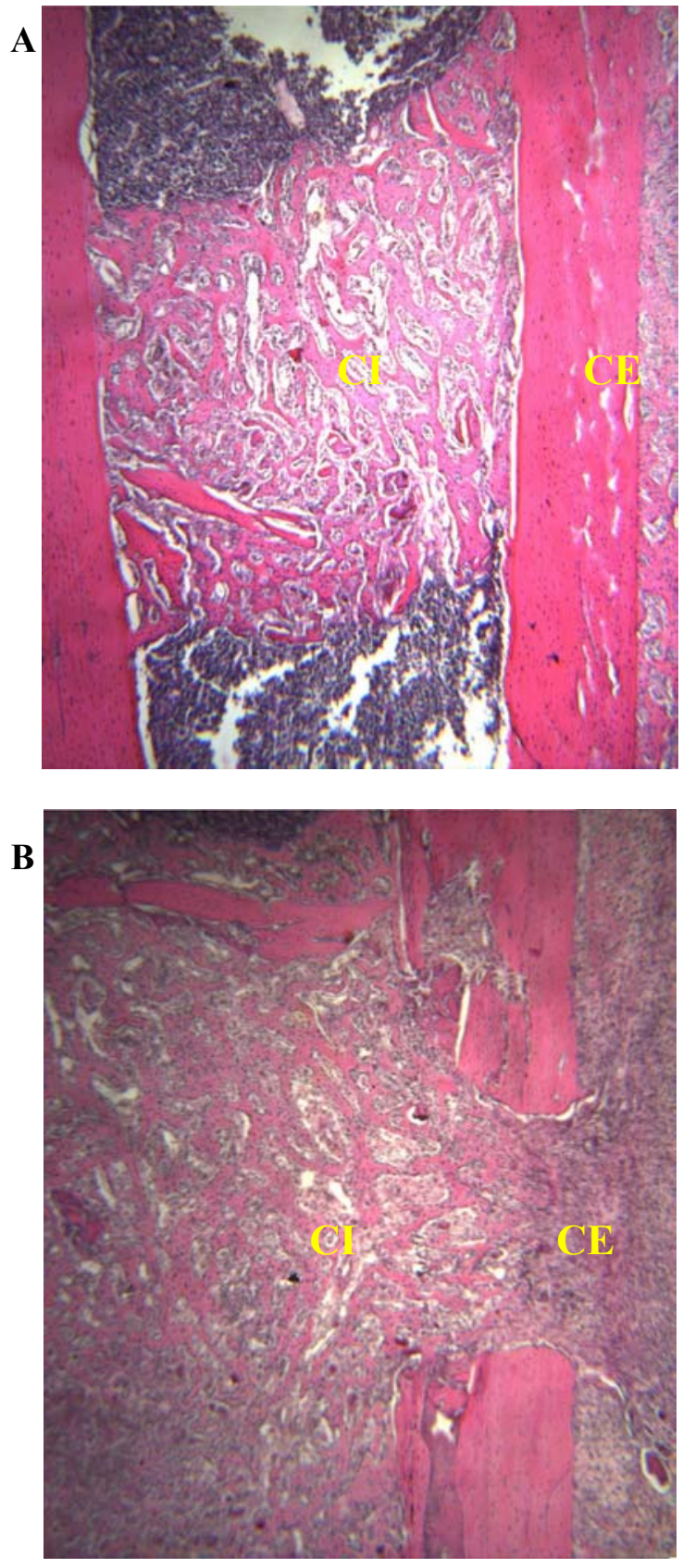

Figura 6. Fotomicrografia de corte longitudinal da tíbia do membro posterior esquerdo de rato, corado com HE. A, tratado com ultra-som de $1 \mathrm{MHz}$ na modulação de pulso de $100 \mathrm{~Hz}$ e $\mathbf{B}$, tratado com ultra-som de $1 \mathrm{MHz}$ na modulação de pulso de $16 \mathrm{~Hz}$. Denotam-se as regiões internas (CI) e externas (CE) do calo relacionadas ao processo de reparo e/ ou regeneração óssea. Aum. 50x. 

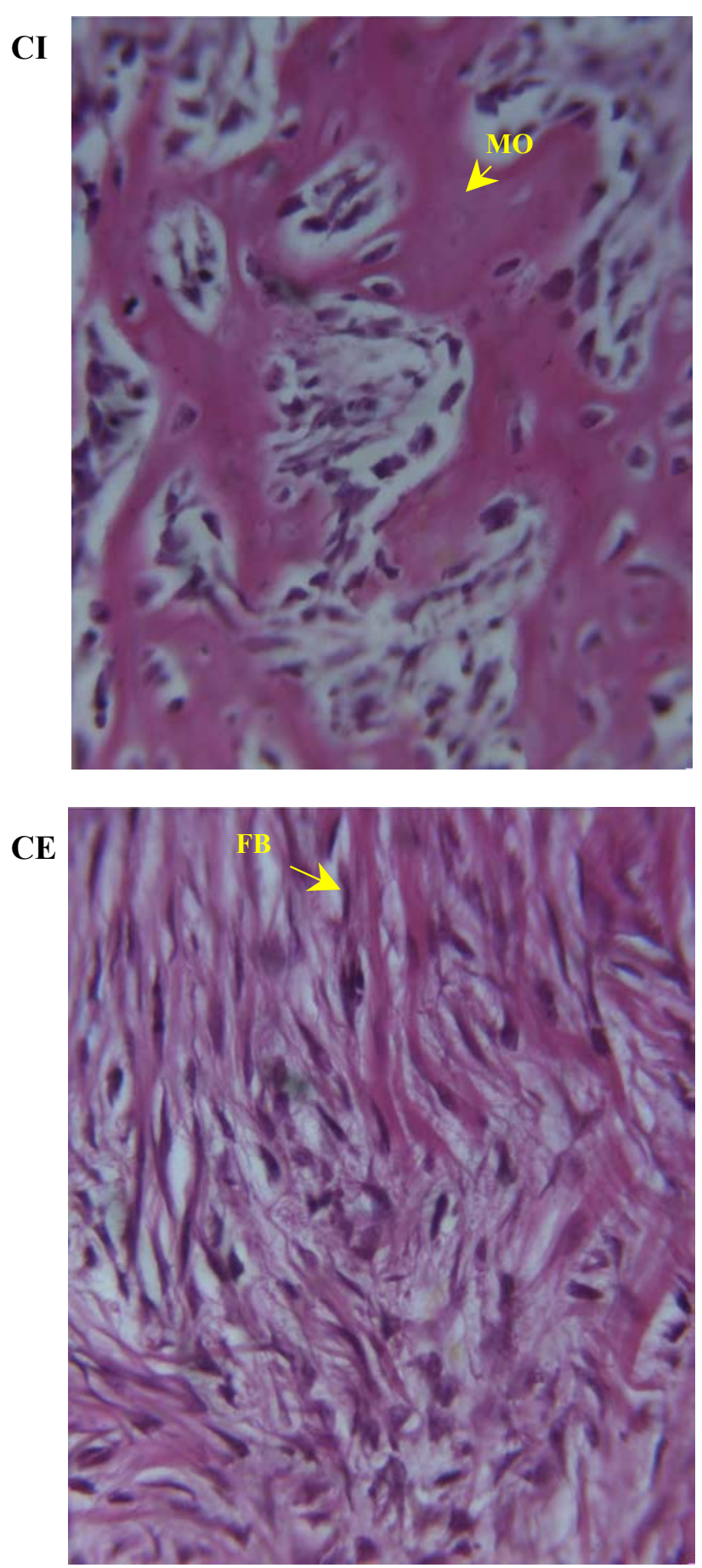

Figura 7. Fotomicrografia do local da osteotomia da tíbia de rato do grupo UST100, corado com HE. CI, calo interno onde se denotam a diminuição do infiltrado inflamatório e aumento na área de matriz óssea (MO) calcificada; no $\mathbf{C E}$, calo externo denotam-se a presença de fibroblastos alinhados (FB) e tecido conjuntivo organizado. Aum. 400x. 

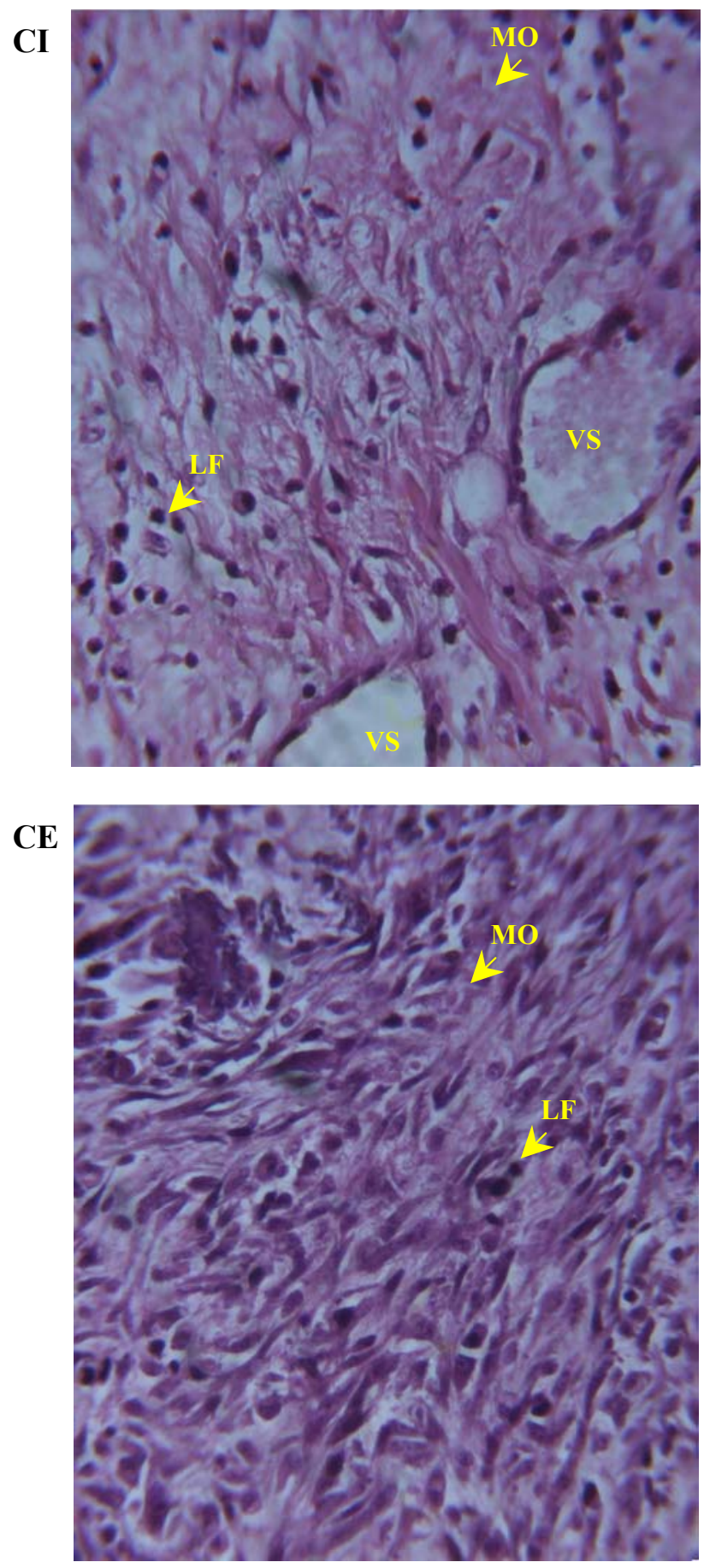

Figura 8. Fotomicrografia do local da osteotomia da tíbia de rato do grupo UST16, corado com HE. CI, calo interno; CE, calo externo. Denotam-se infiltrado inflamatório com presença de linfócitos (LF), matriz óssea (MO) e tecido conjuntivo de aspecto desorganizado. Ainda no CI (calo interno) há presença de vasos sangüíneos (VS). Aum. 400x. 


\subsubsection{Análise morfométrica}

A análise morfométrica mostrou diferenças significativas entre os grupos experimentais (Tab. 1-3). Foram observadas maior densidade de matriz óssea $(47,50 \pm 8,25)$ e menor de fibroblastos $(47,18 \pm 6,69)$ no grupo UST100, quando comparado aos demais grupos experimentais, denotando regeneração óssea. A porcentagem de vasos sangüíneos na região do CI aumentou 400\% no grupo UST16, quando comparados ao controle, um indicador de inflamação crônica.

No grupo controle, a densidade de fibroblastos apresentou-se menor no CI que no CE (Fig. 6; Tab. 3 e 4). No grupo UST100 houve aumento da densidade de fibroblastos no CI $(19,02 \%)$ e no CE $(87,18 \%)$, quando comparados ao controle. No grupo UST16 houve aumento significativo da densidade de fibroblastos tanto no CI $(86,68 \%)$ como no CE (182,35\%), quando comparados ao controle (Fig. 7; Tab. 3, 4 e 5).

A densidade de matriz óssea foi analisada em área específica delimitada na região central da cortical lesada e houve diferenças estatisticamente significavas entre os animais tratados e não-tratados. No grupo no UST100 este aumento foi de 202,00\% enquanto que no grupo UST16 houve um aumento de $24,20 \%$ quando comparados ao grupo controle (Fig. 6, 7 e 8; Tab. 1 e 2).

Em relação à densidade de células inflamatórias, houve diferenças nas densidades de macrófagos, neutrófilos e linfócitos. A densidade de macrófagos do grupo controle foi maior no CI que no CE (Fig. 6; Tab. 3, 4). No grupo UST100 houve diminuição no CI $(73,50)$ e no CE $(33,13 \%)$ (Fig. 7; Tab. 3, 4 e 5). No grupo UST16 houve diminuição $(32,55 \%)$ da densidade de macrófagos no CI e no CE houve aumento $(62,91 \%)$, quando comparados ao controle (Fig. 8; Tab. 3, 4 e 5). 
A densidade de neutrófilos no grupo controle foi maior no CI que no CE (Fig. 6; Tab. 3 e 4). No grupo UST100 houve diminuição no CI $(94,85 \%)$ e aumento no CE (42,37\%) (Fig. 7; Tab. 3, 4 e 5). Comparado também ao controle, no grupo UST16 houve diminuição do CI $(44,14 \%)$ e no CE $(15,25 \%)$, quando comparados ao controle (Fig. 8; Tab. 3, 4 e 5).

A densidade de linfócitos foi significativamente menor no $\mathrm{CI}$ que no $\mathrm{CE}$, no grupo controle (Fig. 6; Tab. 3 e 4). No grupo UST100 houve diminuição no CI (56,72\%) e no CE (93,46\%) (Fig. 7; Tab. 3, 4 e 5) quando comparado ao controle. No grupo UST16 houve diminuição do CI (66,63\%) e no CE $(86,20 \%)$, quando comparados ao controle (Fig. 8; Tab. 3, 4 e 5).

A densidade de vasos sangüíneos do grupo controle foi menor no CI que no $\mathrm{CE}$ (Fig. 6; Tab. 3 e 4). No grupo UST100 a densidade de vasos sanguíneos no calo interno foi igual ao controle. Contudo, não foram observados vasos sanguíneos no calo externo nos campos analisados (Fig. 7; Tab. 3 e 4). Já no grupo UST16 houve aumento significativo no CI (400\%) enquanto que no CE houve diminuição de 44,44\% (Fig. 8; Tab. 3 e 4), comparativamente ao controle. 
Tabela 1 - Densidade de matriz óssea (área de matriz/área teste de $0,0625 \mathrm{~mm}^{2}$ ) determinada em 10 campos aleatórios (média \pm erro padrão da média).

\begin{tabular}{cc}
\hline \hline Grupos experimentais & Matriz óssea \\
\hline Controle & $15,70 \pm 4,61^{\mathbf{a}}$ \\
UST100 & $47,50 \pm 8,25^{\mathbf{b}}$ \\
UST16 & $19,50 \pm 4,62^{\mathbf{a}}$ \\
\hline
\end{tabular}

Letras iguais indicam que não houve diferenças estatisticamente significativas; letras diferentes indicam diferenças significativas $(P>0,05)$.

Tabela 2 - Valores percentuais do aumento da densidade de matriz óssea analisada em área específica delimitada na região central da cortical lesada nos grupos UST100 e UST16, quando comparados ao controle. Aum. 400x.

\begin{tabular}{cc}
\hline \hline Grupos experimentais & Matriz óssea \\
\hline UST100 & $202,00 \%$ \\
UST16 & $24,20 \%$ \\
\hline \hline
\end{tabular}


Tabela 3 - Densidade de estruturas (estruturas $/ 0,0625 \mathrm{~mm}^{2}$ ) determinada em 11 campos aleatórios (média \pm erro padrão da média).

\begin{tabular}{|c|c|c|c|c|c|c|}
\hline \multirow[t]{2}{*}{ Estrutura } & \multicolumn{2}{|c|}{ Controle } & \multicolumn{2}{|c|}{ UST100 } & \multicolumn{2}{|c|}{ UST16 } \\
\hline & CI & CE & CI & CE & CI & $\mathbf{C E}$ \\
\hline Fibroblasto & $39,64 \pm 4,47^{\mathbf{a}}$ & $31,91 \pm 7,20^{\mathbf{a}}$ & $47,18 \pm 6,69^{\mathbf{a}}$ & $59,73 \pm 10,30^{b}$ & $74,00 \pm 9,80^{\mathbf{b}}$ & $90,10 \pm 10,64^{\mathrm{c}}$ \\
\hline Macrófago & $22,64 \pm 6,26^{\mathbf{a}}$ & $16,45 \pm 3,05^{\mathrm{a}}$ & $6,00 \pm 1,29^{\mathbf{b}}$ & $11,00 \pm 2,38^{\mathbf{b}}$ & $15,27 \pm 4,11^{\mathrm{c}}$ & $26,80 \pm 4,05^{\mathbf{c}}$ \\
\hline Neutrófilo & $7,00 \pm 3,57^{\mathbf{a}}$ & $2,36 \pm 0,77^{\mathbf{a b}}$ & $0,36 \pm 0,20^{\mathbf{b}}$ & $3,36 \pm 1,92^{\mathbf{b}}$ & $3,91 \pm 1,68^{\mathbf{c}}$ & $2,00 \pm 0,49^{\mathbf{a c}}$ \\
\hline Linfócito & $8,18 \pm 1,81^{\mathrm{a}}$ & $16,67 \pm 7,41^{\mathrm{a}}$ & $3,54 \pm 2,22^{\mathbf{b}}$ & $1,09 \pm 0,55^{\mathbf{b}}$ & $2,73 \pm 0,66^{\mathbf{b}}$ & $2,30 \pm 0,65^{\mathbf{b}}$ \\
\hline V. sang. & $0,18 \pm 0,21^{\mathbf{b}}$ & $0,54 \pm 0,21^{\mathbf{a}}$ & $0,18 \pm 0,21^{\mathbf{a}}$ & 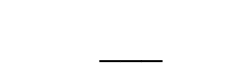 & $0,90 \pm 0,90^{\mathbf{c}}$ & $0,30 \pm 0,21^{\mathbf{c}}$ \\
\hline
\end{tabular}

Letras iguais na mesma linha indicam que não houve diferenças estatisticamente significativas, letras diferentes indicam diferenças significativas (P>0,05). 
Tabela 4 - Valores percentuais da densidade de fibroblastos, macrófagos, neutrófilos, linfócitos e vasos sanguíneos (aumento de 400x) nos grupos UST100 e UST16, quando comparados ao controle.

\begin{tabular}{ccccc}
\hline \hline Estrutura & \multicolumn{2}{c}{ UST100 } & \multicolumn{2}{c}{ UST16 } \\
\cline { 2 - 5 } & CI & CE & CI & CE \\
\hline Fibroblasto & $+19,02 \%$ & $+87,18 \%$ & $+86,68 \%$ & $+182,35 \%$ \\
Macrófago & $-73,50 \%$ & $-33,13 \%$ & $-32,55 \%$ & $+62,91 \%$ \\
Neutrófilo & $-94,85 \%$ & $+42,37 \%$ & $-44,14 \%$ & $-15,25 \%$ \\
Linfócito & $-56,72 \%$ & $-93,6 \%$ & $-66,63 \%$ & $-86,20 \%$ \\
V. sang. & $100,00 \%$ & - & $+400,00 \%$ & $-44,44 \%$ \\
\hline \hline
\end{tabular}

Sinal positivo (+) indica aumento percentual; sinal negativo (-) indica diminuição percentual. 


\section{DISCUSSÃO}

O presente estudo investigou os efeitos do UST de $1 \mathrm{MHz}$ comparando as diferentes modulações de pulso $100 \mathrm{~Hz}$ e $16 \mathrm{~Hz}$ na intensidade $0,5 \mathrm{~W} / \mathrm{cm}^{2}$ (SATA) na fase inflamatória em osteotomia de tíbia de rato. Os parâmetros acústicos usados para intensidade são compatíveis com os aplicados na prática clínica fisioterapêutica (DYSON; BROOKES,1983, TER HARR, 1999; WARDEN; McMEEKEN, 2002; ROBERTSON, 2002; LYON; LIU; MEIER, 2003).

Está bem estabelecido o uso do UST como fonte extrínseca para induzir a osteogênese, promover o reparo e/ou regeneração de fraturas e prevenir a não-união óssea. Estudos experimentais utilizam uma grande variedade de freqüências (1 a 3 $\mathrm{MHz}$ ) e intensidades de UST, que variam entre $0,03 \mathrm{~W} / \mathrm{cm}^{2}$ a $0,5 \mathrm{~W} / \mathrm{cm}^{2}$ (DYSON; BROOKES,1983; DUARTE, 1983; TER HAR, 1999; BUSSE et al., 2002; ROBERTSON, 2002). Alguns estudos demonstram que intensidades acima de 0,5 $\mathrm{W} / \mathrm{cm}^{2}$ tem efeitos deletérios no processo de reparo (REHER et al., 1997; SMITH et al., 2001; HARLE et al., 2001; LYON; LIU; MÉIER, 2003; DEMMINK et al., 2003). De acordo com o estudo realizado por Dyson e Brookes (1983) em fratura completa de fíbula em ratos, utilizando freqüência UST de 1,5 MHz e $3 \mathrm{MHz}$ com intensidade de 0,5 
$\mathrm{W} / \mathrm{cm}^{2}$ e modo pulsado, verificaram que os efeitos do UST são mais efetivos durante as duas primeiras semanas após a lesão, na fase inflamatória e fase proliferativa, antes da formação do calo duro.

De acordo com Doblaré; García e Goméz (2004) o processo de reparo ou regeneração óssea é uma seqüência de eventos biológicos similares aos ocorridos durante a embriogênese e crescimento esquelético. A ossificação endocondral, ossificação intramembranosa e ossificação aposicional (este último tipo praticamente não ocorre em adultos) são ativados durante o processo de reparo de fratura. $\mathrm{O}$ processo de reparo e diferenciação celular passa por dois estágios, o primeiro envolvendo o processo inflamatório, a diferenciação do calo e início da ossificação e no último, continua a ossificação e remodelagem gradual da fratura ocorrendo até o restabelecimento da arquitetura e forma original óssea, processo este que pode levar até um ano. Neste período células mesenquimais podem se diferenciar em condrócitos, osteoblastos ou fibroblastos, dependendo das condições biológicas e mecânicas. Esta diferenciação celular inicia a síntese de matriz extracelular correspondente a cada tipo celular. A matriz óssea intramembranosa origina-se diretamente dos osteoblastos adjacentes ao local da fratura, avançando para o centro do calo e ao mesmo tempo, no centro do calo a cartilagem de revestimento formada por condrócitos e fibroblastos formam matriz óssea por condrogênese, numa seqüência de eventos que incluem maturação e degradação da cartilagem, vascularização e osteogênese.

Neste trabalho, o período escolhido para análise foi de 7 dias (fase inflamatória) que representa com clareza o processo de migração e diferenciação celular utilizada como parâmetro qualitativo e quantitativo do processo de reparo ou regeneração óssea.

A comparação morfológica entre os grupos tratados e o grupo controle e entre os grupos tratados UST100 e UST16 demonstram que o UST acelerou o processo de 
reparo e/ou regeneração óssea e os resultados indicam que o grupo UST100 respondeu melhor ao estímulo ultra-sônico, já que os cortes histológicos apresentam maior aceleração no processo de reparo e maior organização tecidual.

Diversos estudos utilizando a mesma freqüência de UST (1 MHz) sustentam estes resultados. Guerino et al. (1998) utilizaram UST com intensidade de 0,2 W/cm ${ }^{2}$, em osteotomia em tíbia de rato e verificaram que o UST aumentou a resistência da rigidez flexural nos animais tratados quando comparados ao controle. Também Reher et al. (1999) compararam diferentes intensidades em estudo experimental em cultura de células humanas (osteoblastos mandibulares, fibroblastos gengivais e monócitos do sangue) e verificaram que nas intensidades entre 0,1 e $0,5 \mathrm{~W} / \mathrm{cm}^{2}$ houve aumentos estatisticamente significativos na síntese das citocinas IL-8, bFGF e VEGF indicativos de diferenciação e proliferação celular. Os resultados do presente estudo reforçam esses indicativos de proliferação e regeneração tecidual visto que houve maior área de tecido ósseo neoformado, com tratamento por UST. Yang e Park (2001) evidenciaram aceleração da consolidação óssea em fraturas experimentais em ulna de cães através de estudo radiológico utilizando intensidade de $50 \mathrm{~mW} / \mathrm{cm}^{2}$, reforçando os resultados encontrados neste trabalho após analise radiológica. Reher et al. (1997) encontraram aumentos estatisticamente significativas de síntese de proteínas da matriz óssea (colágenas e não-colagenosas) ao estimularem cultura de células da calvária de ratos com 5 dias de idade com intensidades entre 0,1 e $0,5 \mathrm{~W} / \mathrm{cm}^{2}$ e UST de $3 \mathrm{MHz}$. Contudo Schortinghuis et al. (2004a) utilizando UST de 1,5 $\mathrm{MHz}$ com intensidade de 30 $\mathrm{mW} / \mathrm{cm}^{2}$ não encontraram diferenças estatisticamente significativas após análises microradiográficas em osteotomia experimental de mandíbula de rato. Os autores argumentam que provavelmente estes resultados foram causados pela interferência da membrana osteocondutora utilizada neste experimento, bloqueando a passagem da 
energia ultra-sônica. Ainda Schortinghuis et al. (2004b) em estudos complementares sem a utilização da membrana osteocondutora descrevem os mesmos resultados, desconsiderando então, a possibilidade do UST ser efetivo na aceleração da regeneração de fraturas em ossos mandibulares. Entretanto deve ser considerado que o diâmetro da osteotomia utilizado por esses autores pode ser excessivamente grande $(0,5 \mathrm{~mm})$, retardando qualquer resposta de regeneração. Contradizendo estes resultados, Warden et al. (2001) utilizando estes mesmos parâmetros de freqüência e intensidade em estudo in vitro, encontraram resultados estatisticamente significativos após analise de quantificação em PCR de RNAm para expressão gênica de mediadores de resposta inflamatória imediata (c-fos e COX-2) e de expressão de proteínas estimuladoras de matriz óssea (fosfatase alcalina e osteocalcina), quando comparados ao controle, demonstrando aceleração no processo de reparo e/ou regeneração óssea, pelo tratamento com UST. Corroborando com estes resultados, no presente estudo também foram encontrados aumentos nos níveis de fosfatase alcalina, um indicador de deposição de matriz óssea. Sustentando estes resultados, Zhang et al. (2002) encontraram aumentos significativos de colágeno tipo II, X e agrecanas após estimulação ultra-sônica em cultura de células do esterno de embriões de galinhas utilizando estes mesmos parâmetros, por 6 dias consecutivos. Este aumento na expressão de colágeno pode ser relacionado aos resultados do presente estudo, que demonstrou aumento na área de tecido conjuntivo e ossificação. Busse et al.(2002) em estudos envolvendo metanálise encontrou trabalhos que demonstram que a estimulação ultra-sônica pode reduzir substancialmente o tempo de cura e prevenir atraso de consolidação e não-união óssea.

Após a lesão óssea, uma grande variedade de mediadores inflamatórios é liberada e estes não somente iniciam, mas também regulam todos os aspectos do reparo tecidual. Por décadas análises histológicas revelaram o aparecimento de uma seqüência regular 
de diferentes populações celulares durante o processo de reparo da lesão. A eliminação de neutrófilos promove aumento da infecção, mas não resulta em anormalidades no processo de reparo tecidual. A resposta inflamatória mediada por neutrófilos pode ser considerada como um processo múltiplo, envolvendo a adesão inicial de neutrófilos circulantes no endotélio vascular, o subseqüente extravasamento e migração destes para o foco inflamatório. Os neutrófilos possuem papel crucial na primeira linha de defesa contra organismos invasores, na eliminação de corpos estranhos e na remoção de tecidos desvitalizados por fagocitose (GREENHALGH, 1998; STADELMANN; DIGENIS; TOBIN, 1998, DOBLARÉ; GARCÍA; GÓMEZ, 2004; BARR; BARBE, 2004). Tem sido descrito que os neutrófilos têm intensa proliferação no período póslesão imediato, permanecendo assim, freqüentemente, nas primeiras 6 a 24 horas e com o avanço do processo de maturação tende a cair a níveis insignificantes (GREENHALGH, 1998; BARR; BARBE, 2004; FAURSCHOU; BORREGAARD, 2003). Neste estudo comparativo, a densidade de neutrófilos no grupo controle foi maior no CI que no CE. A análise foi realizada aos 7 dias após a lesão, período este considerado avançado para este grupo celular. Considerando que no grupo controle a densidade de neutrófilos foi significativamente maior, observou-se que em ambos os grupos tratados, UST16 e UST100 houve diminuição de densidade de neutrófilos no CI. Tendo em vista que houve maior diminuição no grupo UST100, este tratamento foi mais eficaz, sugerindo uma aceleração do processo inflamatório.

O próximo grupo de células que migram para o local de lesão óssea é o de macrófagos. A eliminação de macrófagos no local da lesão resulta em alteração e atraso no processo de reparo tecidual. Isso sustenta a hipótese de que os macrófagos são as células-chave que regem o reparo tecidual, regulando a liberação de fatores de crescimento e citocinas (GREENHALGH, 1998; DOBLARÉ; GARCÍA; GÓMEZ, 
2004). Neste estudo a densidade de macrófagos do grupo controle foi maior no CI que no CE e em ambos UST16 e UST100 houve diminuição significativa na densidade de macrófagos no CI, sendo que no grupo UST100 esta diminuição foi mais acentuada. Já no CE, no grupo UST100 a densidade de macrófagos foi menor que no controle. Entretanto, no grupo UST16 houve aumento significativo na densidade de macrófagos. Barr e Barbe (2004) descrevem que uma das principais características histológicas da inflamação crônica é o aumento da presença de macrófagos. Estas células fagocitárias contribuem diretamente na manutenção da lesão produzindo enzimas proteolíticas e radicais livres. Assim, o UST de 16 Hz parece induzir inflamação crônica.

Somente após a liberação dos macrófagos acontece o influxo de linfócitos para o local da lesão. Atualmente o papel dos linfócitos no processo de reparo ainda não está totalmente claro, mas os linfócitos liberam muitas citocinas que influenciam a função dos macrófagos e de muitas outras células. A reação inflamatória induzida por leucócitos é essencial para preparar a lesão para a neoprodução de matriz extracelular (GREENHALGH, 1998). De acordo com os resultados destes estudos, a densidade de linfócitos foi significativamente menor no $\mathrm{CI}$ que no $\mathrm{CE}$, no grupo controle. O grupo UST16 apresentou diminuição tanto no CI quanto no CE quando comparados ao controle, no entanto, no grupo UST100 esta diminuição foi mais acentuada tanto no CI quanto no $\mathrm{CE}$ quando comparados ao controle. Os linfócitos são mediadores inflamatórios que permanecem no local por curtos períodos. Neste estudo, a contagem foi realizada aos 7 dias, sua diminuição pode sugerir uma aceleração no processo de regeneração óssea. A menor densidade demonstrada no UST100 parece indicar maior efetividade nesta modulação de pulso, para acelerar a regeneração óssea. A persistência ou aumento no número de linfócitos ocorre quando o tecido é ou continua a ser exposto a microorganismos ou a materiais irritantes, o que não ocorreu neste estudo controlado. 
Os fibroblastos aparecem no local de lesão dentro de 2 a 3 dias e dominam a população de células na primeira semana. A maioria da matriz extracelular recémsintetizada consiste em fibronectina e hialuronato, que servem como arcabouço essencial, no qual os fibroblastos podem migrar e aderir. Os fibroblastos produzem uma variedade de substâncias essenciais para o processo de reparo e regeneração do tecido fraturado, que consistem principalmente em colágeno e glicosanimoglicanas. Este rápido influxo de fibroblastos acontece em média 3 a 5 dias após a lesão óssea (GREENHALGH, 1998; STADELMANN; DIGENIS; TOBIN, 1998). Neste estudo a densidade de fibroblastos no CI aumentou significativamente no grupo UST16 e no grupo UST100 este aumento não foi significativo. Entretanto, no calo externo, o UST16 induziu extremo aumento na densidade de fibroblastos. Grandes aumentos são associados à inflamação crônica visto que estes secretam colágeno e colagenase, precedem a formação de fibrose tecidual e a presença de grande quantidade de calo externo, com alta proporção de cartilagem, é característico de instabilidade do foco de fraturas ou imaturidade do tecido de reparo (BARR; BARBE, 2004; CARANO; FILVAROROFF, 2003; DOBLARÉ; GARCÍA; GOMÉZ, 2004). Sustentando estes resultados, análises radiológicas do presente trabalho, comparando o diâmetro da osteotomia medido com paquímetro digital demonstram diminuições significativas no diâmetro da lesão tanto no grupo UST100 quanto no grupo UST16 quando comparadas ao controle, sendo que no grupo UST100 os diâmetros foram menores, indicando que o tratamento foi mais efetivo. Alguns estudos, mesmo em freqüências ou intensidades diferentes, apresentam resultados passíveis de serem correlacionados aos resultados encontrados neste trabalho. Li et al. (2003) encontraram aumento na atividade mitocondrial dos osteoblastos, aumento na secreção de TGF $\beta 1$ e diminuição de citocinas, que ativam os osteoclastos ao utilizarem o UST $1 \mathrm{MHz}$ pulsado a 20\% com 
modulação de pulso a $100 \mathrm{~Hz}$ na intensidade de $0,6 \mathrm{~W} / \mathrm{cm}^{2}$ (SATP) para estimular a atividade osteoblástica em cultura de células ósseas da calvária de ratos. Observaram ainda um aumento no número de osteoblastos e uma diminuição de osteoclastos. A citocina TGF $ß 1$ estimula a diferenciação de fibroblastos e osteoblastos. Ainda Reher et al. (1997) também em cultura de células ósseas da calvária de ratos verificaram que o UST $3 \mathrm{MHz}$ aplicado em intensidades menores (abaixo de 0,5 W/ $\mathrm{cm}^{2}$ SATA) promoveram maiores aumentos da síntese de proteínas colágenas e não colagenosas. Estas proteínas são sintetizadas por fibroblastos e osteoblastos durante o processo de reparo ósseo.

Os fibroblastos requerem nutrientes e oxigênio para produzir matriz extracelular e novos vasos sanguíneos são formados a partir de vasos pré-existentes, processo este denominado angiogênese (GREENHALGH, 1998; STADELMANN; DIGENIS; TOBIN, 1998). Carano e Filvaroff (2003) descreveram a importância da neoformação de vasos sangüíneos no reparo de fraturas ósseas e que a heterogeneidade da vascularização após lesão óssea ajuda a explicar as diferenças locais da formação óssea normal, retardo de consolidação e das não-uniões. A hipóxia tecidual e a inflamação (presença de monócitos e macrófagos) são fatores capazes de induzir a angiogênese (JACKSON et al., 1997; MUINCK; SIMONS, 2004; CARANO; FILVAROFF, 2003; CROLL et al., 2004). Neste estudo, no CI do grupo UST16 houve um aumento de $400 \%$ na densidade de vasos sangüíneos sugerindo a presença de inflamação crônica. Jackson et al. (1997) demonstraram que existe uma co-dependência entre a angiogênese e a inflamação crônica. Estes autores descreveram que os novos vasos sangüíneos mantêm inflamação crônica por transportar células inflamatórias e suprir de oxigênio e nutrientes o tecido proliferativo inflamado. Contudo, no grupo UST100 a densidade de vasos sangüíneos no CI foi igual ao controle. Não foram observados vasos sangüíneos 
no CE nos campos analisados. Reher et al. (1999) utilizando UST $1 \mathrm{MHz}(0,1$ a 0,4 $\mathrm{W} / \mathrm{cm}^{2}$ ) pulsado a $20 \%$ verificou aumento significativo de IL-8, bFGF e VEGF demonstrando que o tratamento com UST foi efetivo no estímulo de citocinas que estimulam a reparação tecidual e a neoangiogênese.

A atividade sérica da fosfatase alcalina, um produto da diferenciação de osteoblastos, é considerada um espelho do processo de reparo de fraturas e pode ser usada para indicar o início da atividade osteoblástica (LANDRY et al., 1996; LAURER et al., 2000; FARLEY; STILT-COFFING, 2001; IM et al., 2004). No estudo realizado por Laurer et al. (2000) em amostras de sangue humano coletado pós-lesão óssea encontraram dados consistentes de que os níveis séricos sistêmicos da fosfatase alcalina refletem atividade e diferenciação dos osteoblastos. Sustentam também que o pico de secreção desta enzima parece acontecer paralelo ao pico inflamatório e que seus valores tendem a declinar com o aumento do numero de osteoblastos maduros. Em concordância com estes achados, no presente estudo os níveis de fosfatase alcalina foram significativamente diferentes nos grupos experimentais: referência, controle, UST100 e UST16. Os animais submetidos ao tratamento com ultra-som apresentaram níveis séricos mais elevados da enzima fosfatase alcalina, sendo que os animais do grupo UST100 restabeleceram mais rapidamente os níveis basais. Landry et al. (1996) demonstraram em estudo experimental em fraturas de rato, que o início da maturação dos osteoblastos se dá no mínimo 5 dias após a lesão óssea. Os resultados do grupo UST100 parecem indicar uma aceleração do processo de reparo e/ou regeneração óssea. Corroborando com estes resultados Sun et al. (2001), demonstraram que a estimulação do UST $1 \mathrm{MHz}$ com intensidade de $0,068 \mathrm{~W} / \mathrm{cm}^{2}$ por $20 \mathrm{~min}$ do $4^{\circ}$ ao $10^{\circ}$ dia após o inicio da cultura promoveu aumento médio significativo nos níveis de fosfatase alcalina nas amostras analisadas no $7^{\circ}$ dia de cultura quando comparados ao controle. 
A fabricação nacional de aparelhos de UST produzidos de modo a promover uma modulação de freqüência de 16 pulsos por segundo $(16 \mathrm{~Hz})$ provavelmente se baseia na especulação de que a freqüência de $16 \mathrm{~Hz}$ é a fundamental do sistema de cálcio intracelular, portanto, seria considerada a mais efetiva conforme citado por Low e Reed (2001). Não foram encontradas na literatura evidências de "janela" de freqüências ou freqüência de ressonância para o cálcio. É prematuro afirmar que a modulação de freqüência em $16 \mathrm{~Hz}$ é deletéria, mas os indícios sugerem cautela, necessitando de maiores estudos incluindo diferentes intensidades para efetivamente contra-indicar o seu uso. 


\section{CONCLUSÃO}

Os resultados indicam que o tratamento com UST $1 \mathrm{MHz}$ pulsado a 20\%,0,5 W/cm ${ }^{2}$ de intensidade e freqüência de pulso de $100 \mathrm{~Hz}$ foi mais eficiente que o pulsado a $16 \mathrm{~Hz}$, na promoção da regeneração óssea. A freqüência de $16 \mathrm{~Hz}$ demonstrou desorganização tecidual, grande densidade de fibroblastos e vasos sanguíneos indicativos de fibrose e inflamação crônica o que sugere cautela no uso deste aparelho nestas condições para tratamento clínico. 


\title{
7 REFERÊNCIAS BIBLIOGRÁFICAS
}

\author{
ALBERTIN, M. A. Efeito do Ultra-Som no Reparo de Falha Óssea Experimental - \\ Avaliação Quantitativa e Morfológica do Parâmetro Tempo de Estimulação. \\ Dissertação de Mestrado, Escola de Engenharia de São Carlos - Universidade de São \\ Paulo, São Carlos, 1983.
}

BAKER, K.G.; ROBERTSON, V. J.; DUCK, F.A. A review of therapeutic Ultrasound: Biophysical effects. Physical Therapy, v 81, n 7, p 1351-58, 2001.

BARR, A. E.; BARBE, M. F. Inflammation reduces physiological tissue tolerance in the development of work-related musculoskeletal disorders. Journal of Electromyography and Kinesiology, v.14, p. 77-85, 2004.

BARUSHKA, O.; YAAKOBI, T.; ORON, U. Effect of low-energy laser (He-Ne) irradiation on the process of bone repair in the rat tibia. Bone, v. 16, n. 1, p. 47-55, 1995. 
BASSET, C. A. L.; BECKER, R. O. Generation of eletric potentials by bone in response to mechanical stress. Science, v. 137, p. 1063-64, 1962.

BUCKWALTER, J. A.; CRUESS, R. L. A cura dos tecidos musculoesqueléticos. In: ROCKWOOD JÚNIOR, C. A; GREEN, D. P.; BUCHOLZ, R. W. Fraturas em Adultos, vol. 01, $3^{\text {a }}$ ed. São Paulo: Manole, 1993. 179-219 p.

BUSSE, W.J.; BHANDARARI, M.; KULKARNI, A. V.; TUNKS, E. The effect of low-intensity on time to fracture healing: a meta-analysis. Journal Association Medical Canadian, 166 (4), p. 437-441,.2002.

CANCEDDA, R.; DOZI, B.; GIANNONI, P.; QUARTO, R.. Tissue engineering and cell therapy of cartilage and bone. Matrix Biology, v. 22, p. 81-91, 2003.

CARANO, R. A.D.; FILVAROFF, E. H. Angiogenesis and bone repair. Drug Discovery Today v. 8, n. 21, p. 980-989, 2003.

CHAKKALAKAL, D. A.; STRATES, B. S.; MASHOOF, A. A.; GARVIN, K. L.; NOVAK, J. R.; FRITZ, E. D.; MOLLNER, T. J.; McGUIRE, M. H. Repair of segmental bone defects in the rat: an experimental mode human fracture healing. Bone, v. 25, n. 3, p. 321-332, 1999.

CHARMAN, R. A. Strain Generated Potentials in Bone and Connective Tissue. Phisiotherapy, 75(11): 725-730. 1990. 
COLUCCI, A. R. S. Efeitos do ultra-som de baixa intensidade na osseointegração de implantes de titânio em tíbia de coelho: Avaliação histomorfométrica e mecânica. Dissertação de Mestrado, Escola de Engenharia de São Carlos Universidade de São Paulo, São Carlos, 2002.

CORMACK, D. H. Fundamentos de Histologia. Rio de Janeiro: Ed. Guanabara Koogan, 1996. 216-254 p.

CROLL, S. D.; RANSOHOFF, R. M.; CAI, N. ZHANG,Q.; MARTIN,F. J., WEI, T.; KASSELMAN,L. J.; KINTNER, J.; MURPHY, A. J.; YANCOPOULOS, G. D.; WIEGAND, S. J. VEGF-mediated inflammation precedes angiogenesis in adult brain Experimental Neurology, p. 1-15, 2004.

CUNHA, A. PARIZOTTO, N. A.; VIDAL, B. C. The effect of therapeutic ultrasound on repair of the achiles tendon (tendo calcaneus) of the rat. Ultrasound in Medicine and Biology, v. 27, n. 12, p. 1691-1696, 2001.

DOBLARÉ, M.; GARCÍA, J. M.; GÓMEZ, M. J. Modelling bone tissue fracture and healing: a review. Engineering Fracture Mechanics, v. 71, p.1809-1840, 2004.

DUARTE, L.R. The stimulation of bone growth by ultrasound. Archieves of Orthopaedic and Traumatic Surgery, v.101, p.153-159. 1983.

DUARTE, L.R. e XAVIER, C.A.M. Estimulação ultrasônica do calo ósseo. Aplicação clínica. Revista Brasileira de Ortopedia, v.18, n.3, p.73-80, mai./jun. 1983. 
DYSON, M.; BROKES, M. Stimulation of bone repair by ultrasound. Ultrasound in Medicine and Biology, v. 2, p. 61-66, 1983.

DYSON, M. Mechanisms involved in therapeutic ultrasound. Physiotherapy, v. 73, n. 3, p. 116-120, 1987.

DYSON M.; SUCKLING, J., Simulation of repair by ultrasound: a survey the mechanism involved. Physiotherapy, v. 64, n. 4, p. 105-108, 1978.

FAGANELO, F. R.; CARVALHO, D. C. L. Ação do Ultra-Som sobre Fraturas de Ratas Osteopênicas. Trabalho de Graduação, Curso de fisioterapia, Universidade Federal de são Carlos, 1999.

FARLEY, J. R.; STILT-COFFING, B. Apoptosis may determine therelease of skelectal alkaline phosphatase activity from human osteoblast-line cells. Calcified Tissue Intenational, v. 68, p. 43-52, 2001.

FAURSCHOU, M.; BORREGAARD, N. Neutrophil granules and secretory vesicles in inflammation. Microbes and Infection, v.5, p.1317-1327, 2003.

FREEMONT, A. J. Bone. Current Orthopaedics, v. 12, p. 181-192, 1998.

FREITAS, I. G. F.; BARANAUSKAS, V.; CRUZ-HÖFLING, M. A. Lasers effects on osteogenesis. Applied Surface Science, v. 154-155, p. 548-554, 2000. 
FUKADA, E; YASUDA, I. On Piezoeletric Effect of Boné. Journal of Physical Society of Japan, v. 12, n. 10, p 1152-1162, Oct., 1957.

GARDNER, E.; GRAY, D. J; RAHILLY, R. O.; Anatomia, 4a ed: Rio de Janeiro, Guanabara Koogan, 1988

GARNERO, P.; DELMAS, P. D. Biochemical markers of bone turnover: Applications for osteoporosis. Endocrinol. Metab. Clin. N. Am., v. 27, p. 303-323, 1988.

GOUVEA, C. M. C. P.; VIEIRA, P. M. N., AMARAL, A. C. Efeito do ultra-som na recuperação de músculo tibial anterior de rato lesado. Revista da Universidade de Alfenas, v.4, p. 165-173, 1998.

GUERINO, M. R.; LUCIANO, E.; GONÇALVES, M.; LEIVAS, T. P. Aplicação do ultra-som pulsado terapêutico sobre a resistência mecânica na osteotomia experimental. Revista Brasileira de Fisioterapia, v. 2, n. 2, p 63-66, 1997.

GREENHALGH, D. G. The role of apoptosis in wound healing. The International Journal of Biochemistry and Cell Biology, v. 30, p.1019-1030, 1998.

GUYTON, A. C.; HALL, J. E. Tratado de Fisiologia Médica. 9 ${ }^{a}$ ed., Rio de Janeiro: Ed.Guanabara Koogan, 1997. p. 157-159; 782-783.

HARLE, J.; SALIH, V.; MAYIA, F.; KNOWLES, J. C.; OLSEN, I. Effects of ultrasound on the growth and function of bone and periodondal ligament cells in vitro. Ultrasound in Medicine and Biology, v. 27, n. 4 p. 579-586, 2001. 
HEKKENBERG, R. T.; OOSTERBAAN, W. A. Evaluation of ultrasound therapy devices TNO-test, radiation safety and dose accuracy often leave something to be desired Fisiotherapie, v. 96, n. 5, p 112-117, 1985.

HENTHORN, P. S; MILlÁN, J. L; LEBOY, P. in SEIBEL, M. J.; ROBINS, S. P.; BILEZIKIAN, J. P. Dynamics of Bone and Cartilagens Metabolism. USA: Academic Press, cap 9, p 127, 1999.

IM, G.; QURESHI, S. A.; KENNEY, J.; RUBASH, H. E.; SHANBHAG, A. S. Osteoblast proliferation and maturation by biphosphonates. Biomaterials, v. 25, p. 4105-4115, 2004.

JACKSON, J. R.; SEED, M. P.; KIRCHER, K. H.; WILLOUGHBY, D. A.; WINLER, J. D. The codependence of angiogenesis and chronic inflammation The FASEB journal, v.11, p. 457-465, 1997.

JUNQUEIRA, L. C. U.; CARNEIRO J. S. F. Histologia Básica. $7^{\text {a }}$.ed. Rio de Janeiro: Guanabara Koogan, 1990.

KANH, J. Ultrasound in Principles and Practice of Electrotherapy, Churchill Livingstone, NY, 2a. ed., 1991, Cap. 4, p. 51-70

KITCHEN S. S.; PARTRIDGE C. J. A review of therapeutic ultrasound. Part 1: Background and physiological effects. Phisiotherapy, 76(10), p. 593-600, 1990. 
LANDRY, P. S.; MARINO, A. A.; SADASIVAN, K. K.; ALBRIGHT, J. A.; Bone injury response. $\mathrm{Na}$ animal model for testing theories of regulation. Clinical Orthopaedics and Related Research, v. 332, p. 260-273, 1996.

LAURER H.L.; HAGENBOURGER O.; QUAST S.; HERRMANN W.; MARZI I. Sequential changes and pattern of bone-specific alkaline phosphatase after trauma. European Journal of Trauma, n1, p. 33-38, 2000.

LI, J. K; CHANGA, W. H.; LIN, J. C, RUAAN, R. C.; LIUC, H. C.; SUN, J. S. Cytokine release from osteoblasts in response to ultrasound stimulation. Biomaterials, v. 24, p. 2379-2380, 2003.

LEHMANN, J. F., DE LATEUR, B. J. Diatermia e calor superficial, laser e crioterapia. In: KROTE, F. J.; LEHMANN, J. F. Tratado de medicina física e reabilitação de KRUSEN. $4^{\text {a. }}$ ed. Rio de Janeiro: Manole Ltda, 1994.

LOW, J.; REED, A. Eletroterapia explicada- Princípios e prática, $3^{\mathrm{a}}$. ed. São Paulo: Manole, 2001.

LYON, R.; LIU, X. C.; MEIER, J. The effects of therapeutic vs. high-intensity ultrasound on the rabbit growth plate. Journal of Orthopaedic Research, v. 21, p. 865$871,2003$. 
MARINO, J. A. M. Efeito do laser terapêutico de baixa potência sobre o processo de reparação óssea em tíbia de rato. Dissertação Mestrado. Universidade Federal de São Carlos, São Carlos, 2003.

MUINCK, E. D; SIMONS, M. Re-evaluating therapeutic neovascularization Journal of Molecular and Cellular Cardiology, v. 36, p. 25-32, 2004.

ONI, O. A. The bony callus, Injury, v. 28 n. 9-10, p. 629-631, 1997.

PILLA, A. Low-intensity electromagnetic and mechanical modulation of bone growth and repair: are they equivalent? Journal Orthopaedic Science, v.7, p.420-428, 2002.

REHER, P.; DOAN, N.; BRADNOCK, B.; MEGHJI, S.; HARRIS, M. Effect of ultrasound the production of IL-8, basic FGF and VEGF. Cytokine, v. 11, n.6, p 146423, 1999.

REHER, P.; EL-NOOR, I. ELBESHIR; HERVEY, W.; MEGHJI, S.; HARRIS, M. The stimulation of bone formation in vitro by therapeutic ultrasound. Ultrasound in Medicine and Biology, v. 23, n. 8 p. 1251-1258; 1997

ROBERTSON, V. J. Dosage and treatment response in randomized clinical trials of therapeutic ultrasound. Physical Therapy in Sport, v. 3, p. 124-133, 2002. 
SCHORTINGHUIS, J.; RUBEN, J. L; RAGHOEBAR, G. M.; STEGENGA, B. Therapeutic ultrasound to stimulate osteoconduction: A placebo controlled single blind study using e-PTFE membranes in rats, Archives of Oral Biology v. 49, p. 413-420, 2004a.

SCHORTINGHUIS, J.; RUBEN, J. L; RAGHOEBAR, G. M.; STEGENGA, B. Ultrasound to stimulate mandibular bone defect healing: a placebo-controlled singleblind study in rats, Journal Oral Maxillofacial Surgery, v.62, p.194-201, 2004b.

SEIBEL, M. J.; ROBINS, S. P.; BILEZIKIAN, J. P. Dynamics of bone and cartilagens metabolism. USA: Academic Press, 1999.

SILVA, O. L. Estudo do mecanismo de ação do ultra-som na estimulação de crescimento ósseo. Dissertação de Mestrado, Escola de Engenharia de São Carlos Universidade de São Paulo, 1987.

SMITH, N. B.; TEMKIN, J. M.; SHAPIRO, F.; HYNYNEN, K. Thermal effects of focused. Ultrasound in Medicine and Biology, v. 27, n. 10, p. 1427-33, 2001.

StADELMANN, W. K.; DIGENIS, A. G.; TOBIN, G. R. Physiology and healing dynamics of chronic cutaneous wounds. The American Journal Of Surgery, v. 176, Supl. 2A, p. 27s-38s, 1998.

SUN, J.S.; HONG, R. C.; CHANG, W. H.; CHEN, L. T.; LIN, F. H.; LIU, H. C., In vitro effects of low-intensity ultrasound stimulation on the bone cells, Journal Biomed Mater Res; v.57, p.449-456, dec 5, 2001. 
TANZER, M.; KANTOR, S.; BODYN, J. D. Enhancement of bone growth into porous intramedullary using non-invasive low intensity ultrasound. Journal Orthopaedic Research, v.19, p 195-199, 2001.

ter HAAR, G. Basic physics of therapeutic ultrasound. Phisiotherapy, v. 73, p.110-113, 1987.

TORTORA G. J.; GRABOWSKI, S. R. Princípios de anatomia e fisiologia 9a ed. Rio de Janeiro: Guanabara Koogan, 2002.

TUREK, S.L. Ortopedia: princípios e sua aplicação. v.1. São Paulo: Manole, p. 31107, 1991.

WARDEN, S. J.; MCMEEKEN, J. M. Ultrasuond usage and dosage in soports physiotherapy. Ultrasound in Medicine and Biology, v. 28, n. 8, p. 1075-1080, 2002.

WARDEN, S. J.; FAVALORO J. M.; BENNELL, K. L.; MCMEEKEN, J. M; NG, KONG-WAH;. ZAJAC, J D; WARK, J D. Low-intensity pulsed ultrasound stimulates a bone-forming response in UMR-106. Cells Biochemical and Biophysical Research Communications, v. 286, p. 443-450, 2001.

WILliamS, R. Production and transmission of ultrasound. Phisiotherapy, v. 73, p.113-116, 1987. 
YAAKOBI, T.; MALTZ, L.; ORON, U. Promotion of bone repair in the cortical bone of the tibia in rats by low energy laser (He-Ne) irradiation. Calcified Tissue International, v. 59, p. 297-300, 1996.

YANG, K.; PARK, S. stimulation of fracture healing in a canine ulna full-defect model by low-intensity pulsed ultrasound. Yonsei Medical Journal, v.42, n. 5, p. 503-508, 2001.

ZHANG, Z.; HUCKLE, J.; FRANCOMANO, C. A.; SPENCER, R. G. S. The influence of pulsed low-intensity ultrasound on matrix production of chondrocytes at different stages of differentiation: An explant study. Ultrasound in Medicine and Biology, v. 28, n. 11/12, p.1547-1553, 2002. 